Published in final edited form as:

Neurobiol Dis. 2015 December ; 84: 4-21. doi:10.1016/j.nbd.2015.04.020.

\title{
Oxidative and Nitrative Stress in Neurodegeneration
}

\author{
Catherine A. Cobb ${ }^{1}$ and Marsha P. Cole ${ }^{1,2}$ \\ ${ }^{1}$ Department of Biochemistry and Molecular Genetics, School of Medicine, University of \\ Louisville, Louisville, KY, 40202 \\ 2Department of Physiology and Biophysics, School of Medicine, University of Louisville, \\ Louisville, KY, 40202
}

\begin{abstract}
Aerobes require oxygen for metabolism and normal free radical formation. As a result, maintaining the redox homeostasis is essential for brain cell survival due to their high metabolic energy requirement to sustain electrochemical gradients, neurotransmitter release, and membrane lipid stability. Further, brain antioxidant levels are limited compared to other organs and less able to compensate for reactive oxygen and nitrogen species (ROS/RNS) generation which contribute oxidative/nitrative stress (OS/NS). Antioxidant treatments such as vitamin E, minocycline, and resveratrol mediate neuroprotection by prolonging the incidence of or reversing OS and NS conditions. Redox imbalance occurs when the antioxidant capacity is overwhelmed, consequently leading to activation of alternate pathways that remain quiescent under normal conditions. If OS/NS fails to lead to adaptation, tissue damage and injury ensue, resulting in cell death and/or disease. The progression of OS/NS-mediated neurodegeneration along with contributions from microglial activation, dopamine metabolism, and diabetes comprise a detailed interconnected pathway. This review proposes a significant role for OS/NS and more specifically, lipid peroxidation (LPO) and other lipid modifications, by triggering microglial activation to elicit a neuroinflammatory state potentiated by diabetes or abnormal dopamine metabolism. Subsequently, sustained stress in the neuroinflammatory state overwhelms cellular defenses and prompts neurotoxicity resulting in the onset or amplification of brain damage.
\end{abstract}

\section{Keywords}

Oxidative stress; Nitrative stress; Lipid peroxidation; Neurodegeneration; Microglial activation; Dopamine metabolism; Reactive oxygen species; Reactive nitrogen species; Brain; Lipid/Protein modification

Correspondence: Marsha P. Cole, PhD University of Louisville, Department of Biochemistry and Molecular Genetics School of Medicine 580 South Preston Street, Delia Baxter II Bldg, Room 102C Louisville, KY, 40202 Phone: (502) 852-7157; marcie.cole@louisville.edu.

Publisher's Disclaimer: This is a PDF file of an unedited manuscript that has been accepted for publication. As a service to our customers we are providing this early version of the manuscript. The manuscript will undergo copyediting, typesetting, and review of the resulting proof before it is published in its final citable form. Please note that during the production process errors may be discovered which could affect the content, and all legal disclaimers that apply to the journal pertain. 


\section{BACKGROUND}

\section{Lipid Peroxidation in the Brain}

Polyunsaturated fatty acids (PUFAs) such as linoleic acid and arachidonic acid are remarkably abundant lipids that occupy neuronal membranes among other locations, yet are also the principal targets of oxidation attributed to the presence of one or several nucleophilic unsaturated double bonds; PUFA oxidation triggers a redox cycle that will engender further PUFA oxidation (Sultana et al., 2013, Shichiri, 2014). However, if the cell's antioxidant capabilities are exhausted or impaired, PUFA oxidation and consequent damage will proliferate unabated, initiating cell death.

Lipid peroxidation (LPO) occurs in three distinct stages: initiation, propagation, and termination (Fig. 1). Hydrogen abstraction from or reactive oxygen species (ROS) addition to the PUFA marks the initiation stage where it transitions into the propagation stage. Propagation is characterized by the oxidized PUFA reacting with molecular oxygen to generate a lipid peroxyl radical. The lipid peroxyl radical attacks another PUFA to then react with oxygen and form a lipid peroxyl radical, instigating an infinite chain reaction from one initial attack unless termination occurs. Termination can arise from two different mechanisms: two radicals or peroxyl radicals can conjugate each other or an antioxidant can quench the last radical formed. PUFA oxidation leads to the enzymatic or non-enzymatic generation of multiple $\alpha, \beta$-unsaturated aldehyde end-products. They are introduced below along with oxidative damage-dependent products and lipid and protein modifications.

LPO directly affects membrane fluidity, which results in altered membrane protein activity and molecular localization to the membrane. LPO also may disrupt membrane efficacy as a barrier (Sultana et al., 2013).

\section{Lipid Peroxidation Products}

Brain cell-derived ROS coupled with stressful conditions can induce LPO product formation, shifting redox homeostasis. Once an imbalanced redox state occurs, often referred to as compensatory oxidative stress, several mechanisms attempt to ameliorate the shift allowing the cell to handle the flux in ROS. In neurodegenerative disorders, these compensatory mechanisms can lead to decompensation, resulting in accumulated LPO products that are characteristic of several central nervous system (CNS) diseases, further triggering transformations in antioxidant machinery, protein degradation, organelle clearance, mitochondrial dysfunction, or glial activation. The reactive aldehydes resulting from LPO are described below.

Acrolein-Acrolein is a water-soluble, highly reactive $\alpha, \beta$-unsaturated aldehyde formed from lipid autoperoxidation, which requires a carbon-carbon bond cleavage event, or as a natural byproduct present in the environment from car exhaust among other examples (Shichiri, 2014). Under antioxidant-poor conditions, acrolein can persist as an intracellular cytotoxin via stable thiol generation through its quick, irreversible reactions with sulfhydryl groups (Tully and Shi, 2013). 
4-HNE-4-hydroxy-2-nonenal (4-HNE) is a diffusible, cytotoxic, a, $\beta$-unsaturated aldehyde and major LPO end-product. 4-HNE reacts via Michael addition, forming covalent bonds to the amino acids cysteine, histidine, and lysine, as well as nucleic acids (Shichiri, 2014). Specifically, Michael addition is a 1, 4 addition reaction where a nucleophilic carbon compound adds to an electrophilic, a, $\beta$-unsaturated compound (Baker et al., 2007, Ayala et al., 2014).

MDA-Malondialdehyde (MDA) is a mutagenic a, $\beta$-unsaturated aldehyde which is commonly used as a biomarker for LPO via the thiobarbituric acid reacting substance (TBARS) assay (Ayala et al., 2014). The assay measures MDA's reaction with thiobarbituric acid through formation of a quantifiable red product measured by spectrophotometry. The primary drawback to this assay is its lack of specificity for MDA. Sample storage is a secondary consideration: in temperatures above $-70^{\circ} \mathrm{C}$ and/or the presence of light can promote further oxidation and overestimate the results.

\section{ROS/RNS, Superoxide and Nitric Oxide}

Normal metabolism yields free radicals which are used in cellular processes such as the immune response, vasomotor tone, and signaling and are later neutralized by cellular antioxidant machinery. Free radicals are highly reactive molecules attempting to satisfy an unpaired electron. Free radicals include superoxide $\left(\mathrm{O}_{2}{ }^{\bullet-}\right)$, nitric oxide $\left({ }^{\circ} \mathrm{NO}\right)$, hydroxyl radicals $\left({ }^{\circ} \mathrm{OH}\right)$, and peroxyl radicals $(\mathrm{ROH})$ along with additional non-radical molecules such as peroxynitrite $\left(\mathrm{ONOO}^{-}\right)$and hydrogen peroxide $\left(\mathrm{H}_{2} \mathrm{O}_{2}\right)$ (Sultana et al., 2013). These are divided into ROS, which include $\mathrm{O}_{2}{ }^{\cdot-},{ }^{\bullet} \mathrm{OH}, \mathrm{ROH}$, and $\mathrm{H}_{2} \mathrm{O}_{2}$, and reactive nitrogen species (RNS), which include ${ }^{\circ} \mathrm{NO}$ and $\mathrm{ONOO}^{-}$.

Superoxide and Hydrogen Peroxide-Xanthine oxidase (XO), the NADPH oxidase (NOX) family, and mitochondria all contribute to superoxide production (Fig. 2).

Superoxide is not the most reactive free radical but is a precursor to the formation of highly reactive ROS. Following $\mathrm{O}_{2}{ }^{--}$production, several cellular defense mechanisms are activated. The enzymatic activities of superoxide dismutase (SOD), catalase (CAT), and glutathione peroxidase (GPx) represent exemplary mechanisms for ROS detoxification and clearance, hindering the onset of or lessening the deleterious effects from OS. SOD combines $\mathrm{O}_{2}{ }^{*-}$ with protons to form $\mathrm{H}_{2} \mathrm{O}_{2}$, which acts as a substrate for both CAT and GPx, but can also react with iron (Pong, 2003). CAT uses $\mathrm{H}_{2} \mathrm{O}_{2}$ to yield molecular oxygen and water, whereas GPx uses $\mathrm{H}_{2} \mathrm{O}_{2}$ and reduced glutathione (GSH) to form water and oxidized glutathione (GSSG). The bioavailability of GSH is a critical limiting factor for GPx activity. Ferrous iron reacts with $\mathrm{H}_{2} \mathrm{O}_{2}$ in a Fenton reaction generating $\mathrm{OH}^{-}$and ${ }^{\circ} \mathrm{OH}$. Ferric iron can also react with $\mathrm{HO}_{2}$ to generate ${ }^{\circ} \mathrm{OOH}$ and $\mathrm{H}^{+}$(Winterbourn, 1995).

Nitric Oxide-Nitric oxide is an easily diffusible, short-lived gas molecule that acts through guanylate cyclase and is utilized in vasodilation, perfusion, inflammation, and nerve transmission (Moncada and Bolanos, 2006). Nitric oxide is produced by the nitric oxide synthase (NOS) enzyme family, which is comprised of three tissue-specific isoforms, neuronal NOS (nNOS; NOS1), inducible NOS (iNOS; NOS2), and endothelial NOS (eNOS; NOS3) (Fig. 2). nNOS and eNOS are constitutively expressed; iNOS requires a stimulus, 
thus it is inducible. L-arginine, NADPH, and molecular oxygen are substrates for all NOS isoforms, forming ${ }^{\circ} \mathrm{NO}$, citrulline, and water (Smith and Lassmann, 2002). NOS enzymes require essential cofactors including flavin mononucleotide (FMN), flavin adenine dinucleotide (FAD) tetrahydrobiopterin $\left(\mathrm{BH}_{4}\right)$, heme, and $\mathrm{NADPH}$. When the $\mathrm{BH}_{4}$ pool is depleted, NOS can instead contribute to $\mathrm{O}_{2}{ }^{*-}$ production (Moncada and Bolanos, 2006).

\section{ONOO- and 3-NT}

Peroxynitrite production is a consequence of the diffusion-limited reaction between ${ }^{\circ} \mathrm{NO}$ and $\mathrm{O}_{2}{ }^{\circ-}$ and tends to form proximally to the source of $\mathrm{O}_{2}{ }^{*-}$, as $\mathrm{O}_{2}{ }^{*-}$ is the more short-lived of the two reactants. Peroxynitrite can be protonated and undergo homolytic cleavage into nitrogen dioxide radical $\left({ }^{\circ} \mathrm{NO}_{2}\right)$ and ${ }^{\circ} \mathrm{OH}$ (Hogg and Kalyanaraman, 1999). Subsequently, the newly formed ${ }^{\circ} \mathrm{NO}_{2}$ can give rise to protein tyrosine nitration (3-NT) as described in the following paragraph. Even though $\mathrm{ONOO}^{-}$may possess antimicrobial activities, its currently documented effects are damaging to cells, tissues, and organs (Radi, 2013a).

Resulting from $\mathrm{ONOO}^{-}$-dependent ${ }^{\circ} \mathrm{NO}_{2}$ generation, 3-NT is a post-translational protein modification that can alter a protein's normal structure and function. An ${ }^{\circ} \mathrm{NO}_{2}$ group adds to the aromatic side chain of tyrosine after an oxidant radical abstracts tyrosine's proton to form a tyrosyl radical (Radi, 2013a). 3-NT formation above basal levels indicates an OS environment enriched in nitrosative species, which correlates to disease progression and severity. Protein tyrosine nitration is reviewed more in-depth in these articles (Rubbo and Radi, 2008, Radi, 2013b). 3-NT can be measured using an anti-3-NT antibody (Franco et al., 2013) or by chemical means through chromatographic techniques (Yeo et al., 2014).

\section{SNO}

S-nitrosylation (SNO) is a reversible post-translational modification in proteins. This modification is caused by the addition of an $\mathrm{NO}$ group to side chain thiols in cysteine residues. SNO can be detected by chemiluminescence, anti-SNO antibodies, mass spectrometry, and biotin switch assays of which mass spectrometry would give the greatest sensitivity and specificity. For greater detail outside the scope of this manuscript, refer to this recent review on SNO modification and detection (Chen et al., 2013).

\section{$\cdot \mathrm{NO}_{2}$ Lipid Nitration}

Nitrogen dioxide radical can result from oxidation of $\mathrm{NO}$ within cells or the decomposition of nitrite in a low $\mathrm{pH}$ environment into ${ }^{\circ} \mathrm{NO}$ and ${ }^{\circ} \mathrm{NO}_{2}$ (Fig. 2). Thus, formation of ${ }^{\circ} \mathrm{NO}_{2}$ is dependent on the presence or absence of molecular oxygen as well as hydrogen ion concentration. Nitrogen dioxide radicals can initiate the cycle of LPO where lipids, by homolytic attack of ${ }^{\circ} \mathrm{NO}_{2}$, produce nitroalkyl radicals or carbon-centered radicals (Hogg and Kalyanaraman, 1999). Nitroalkyl radicals go on to yield either nitroalkenes resulting from a second $\mathrm{NO}_{2}$ reaction and loss of nitrous acid or nitro-allyl or -hydroxy derivatives. Hydrogen abstraction leads to nitro-allyl derivative formation whereas hydrolysis ends with the production of nitro-hydroxy derivatives. 


\section{$\mathrm{NO}_{2}^{+}$Lipid Nitration}

Nitronium $\left(\mathrm{NO}_{2}^{+}\right.$), or nitryl, ions can be produced via reaction of $\mathrm{ONOO}^{-}$and one of the 38 transition metals to eliminate an electron from nitrogen dioxide $\left(\mathrm{NO}_{2}\right)$ or adding a hydrogen to nitric acid (Kono, 1995). As a stable electrophile, $\mathrm{NO}^{+}{ }_{2}$ can attack nucleophilic double bonds in lipids (O'Donnell et al., 1999).

\section{Oxidative Damage and Protein/Lipid Nitration}

There are several ways in which proteins and lipids can be structurally altered due to nitrative and nitrosative stress (Fig. 2). The protein modifications necessary for this review are 3-NT by $\mathrm{ONOO}^{-}$and $\mathrm{SNO}$ of cysteine residues. These protein modifications occur in the normal cellular environment and when present in enhanced concentrations in neurodegenerative conditions, they can cause shifts in enzymatic activity, metabolism, and cell maintenance processes like autophagy and the proteasomal-ubiquitin system, all of which are critical to cell function and may result in cell death.

Lipid nitration resulting from the presence of $\mathrm{ONOO}^{-},{ }^{-} \mathrm{NO}_{2}$, or $\mathrm{NO}_{2}{ }_{2}$ can occur on unsaturated fatty acids (O'Donnell et al., 1999). The affinity for nitrative modifications varies among fatty acids by double bond reactivity, i.e. conjugated dienes exhibit greater reactivity than fatty acid monoalkenes (Bonacci et al., 2012). It has recently been determined that conjugated linoleic acid is the favored target for fatty acid nitration in vivo (Bonacci et al., 2012). These modifications are regulated by physiological levels of the nitrating species, their targets, the ratio of ROS to RNS, and antioxidants; local sites of RNS production; and the presence of oxygen. Nitrated fatty acids $\left(\mathrm{NO}_{2}-\mathrm{FA}\right)$ mediate antiinflammatory signaling (Freeman et al., 2008, Rudolph and Freeman, 2009, Fazzari et al., 2014). In addition, $\mathrm{NO}_{2}$-FA have been shown to participate in the onset of inflammation and to affect both vasomotor tone and several signaling pathways, namely heme oxygenase-1 (HO-1), nuclear factor kappa light chain enhancer of activated B cells (NF-kB), and peroxisome proliferator-activated receptors (PPARs) (Freeman et al., 2008), where $\mathrm{NO}_{2}$-FA serve as a redox sensor to relay the oxidative status of the intra- and extracellular environments within organisms.

\section{Cellular Detoxification and Clearance of ROS and RNS}

The key mediators of OS, ROS and RNS, are produced during normal metabolism and provide signaling for maintenance of cellular health and function. To preserve the overall homeostatic redox balance, cells employ primary strategies including the aforementioned SOD, CAT, and GPx activities. However additional molecules involved in redox cycling reactions include vitamin E, lipoic acid (LA), and ascorbic acid (also known as vitamin C) whose functions are to terminate LPO and scavenge free radical species. Further, synthetic derivatives such as the vitamin E analog CR-6 have been shown to have antioxidant effects. Additionally, apolipoprotein D (ApoD) can sequester or stabilize membrane-bound lipids and LPO precursors like arachidonic acid through binding (Dassati et al., 2014). ApoD can also generate non-reactive lipid hydroxides through the reduction of lipid hydroperoxides (Dassati et al., 2014). As the bioavailability, synthesis, and dietary uptake of antioxidants fluctuates, cells maintain an OS-free state by an integrated system in the turnover of ROS and RNS with contributions from both dietary and enzymatic pathways. 


\section{INTRODUCTION}

\section{Signaling in Disease and Alternate Pathological States}

The LPO products and protein and lipid modifications mentioned above regulate or contribute to the processes directly or indirectly linked to the progression of neurodegeneration. This review will argue that in neurodegeneration, the brain is in a constitutively reactive state characterized by a gradual disequilibrium in redox homeostasis. The shift in redox signaling is due to microglial activation (MGLA), altered dopamine (DA) metabolism, and diabetes. All of these are described below along with their roles in modulating the primary players or processes specific to each of the following pathologies: Huntington's disease (HD), Alzheimer's disease (AD), Parkinson's disease (PD), multiple sclerosis (MS), epilepsy and seizures, PDN, lysosomal storage diseases (LYSD), glaucoma, human immunodeficiency virus (HIV), traumatic brain injury (TBI), aging, and sedentary lifestyles.

\section{Microglial Activation}

Microglia are neuronal support cells from mesodermal origins categorized as a subset of macrophages specific to the CNS. Other glial cell populations in the nervous system include astrocytes and oligodendrocytes. Although microglial function in the healthy or unaffected nervous system is largely unknown, their function in diseased conditions can be beneficial or harmful, suggesting complex mechanisms are at play (Yenari et al., 2010, Tan et al., 2012, Rawji and Yong, 2013). As support cells, their roles upon activation are to determine whether a neuron is salvageable (neutrotrophic) or should be cleared (neurotoxic). Factors such as a preexisting neurodegenerative condition or imbalanced redox cycling can prompt chronic, dysfunctional MGLA, which can predispose microglia to behave abnormally and preserve a neurotoxic state even if neurons can be repaired.

Microglia are present in a resting or inactive state until a stimulus activates them. Triggers for MGLA include ROS/RNS, aging, inflammation, and cytokine release during trauma or neurodegeneration. When activated, microglia induce iNOS expression, release cytokines, and contribute to an OS condition. All of this leads to neuroinflammation and consequent neurotoxicity. For example, MGLA can instigate excessive generation of dopaminequinones (DQ), deviating from normal DA metabolite production. The presence of DQ can sustain MGLA and down regulate the expression of neuroprotective genes (Kuhn et al., 2006). A destructive cycle then begins where the neurotoxic inflammatory end point represents a positive feedback loop: neurotoxicity sustains MGLA, and the cycle continues until either a step in the process is inhibited or death of the cell or organism occurs similar to the cycle of LPO (Fig. 3). Thus, MGLA is a consequence of or a preceding step toward OS in the brain.

\section{Dopamine Metabolism}

DA metabolism is linked to microglial function (Farber et al., 2005), regulation of enzymatic modifications (Ara et al., 1998, Park et al., 2003, Belluzzi et al., 2012), glucose and insulin homeostasis (Williams et al., 2007), and acetylcholine (ACh) induced nerve transmission (Allen et al., 2011, Suo and Ishiura, 2013). When DA metabolism is altered, 
the subsequent OS results in the formation of cytotoxic downstream mediators such as LPO products and ROS. In particular, $\mathrm{ONOO}^{-}$formation leads to nitration of proteins involved in the DA metabolic pathway, as well as proteins involved in apoptosis. Additionally, DQ production down regulates antioxidant enzyme expression and increases ROS. DA signaling and MGLA may contribute to neurodegeneration along with the sensitivity to OS resulting from the presence of diabetes.

\section{Roles of Oxidative/Nitrative Stress in Neurodegenerative Disease States}

Huntington's Disease (HD)—Huntington's disease is a genetically inherited autosomal dominant condition arising from an expansion of cytosine-adenine-guanine (CAG) tandem repeats in the huntingtin $(\mathrm{Htt})$ gene. Thus, the encoded mutant huntingtin (mHtt) protein expresses a recurring sequence of additional unnecessary tandem glutamine, or polyQ, residues. Although the exact role for the Htt protein is still unclear, functions associated with it are beneficial to the health of neurons as well as their sustained survival (Cattaneo et al., 2005). Expression of $\mathrm{mHtt}$ triggers shifts in several critical neuronal processes. Under normal conditions, chaperone proteins correct the abnormally folded $\mathrm{mHtt}$ protein that is proteolytically cleaved into fragments in the cytoplasm. The remnants then undergo ubiquitination to tag them for proteasomal degradation. When the proteasome or autophagy machinery is impaired, $\mathrm{mHtt}$ fragments accumulate intracellularly. Consequently, the expanded repeat-containing fragments can interact with other proteins and disrupt calcium signaling and mitochondrial function, whereas the amino-terminal fragments can alter gene expression or manufacture inclusions in the nucleus upon nuclear translocation (Zuccato et al., 2010).

Notably, OS can affect mitochondrial, proteasomal, and autophagic proteins, affecting their activities. It is possible that neurodegeneration in HD beginning with the $\mathrm{mHtt}$ protein is mediated by an increase in OS caused by $\mathrm{mHtt}$ aggregation and accumulation. This may potentiate the decreased clearance of $\mathrm{mHtt}$ in neurons. The studies below detail how animal models of HD are linked to changes in the OS status of the brain and its contribution to neuronal function or dysfunction. Animal models available for HD include excitotoxic models [kainic acid (KA), quinolinic acid (QUIN)], mitochondrial disrupters [malonic acid, NMDA, and 3-nitropropionic acid (3-NP)], and genetic models with stable or inducible expression of Htt or mHtt (Cepeda et al., 2010). However, the studies mentioned in this section focus on QUIN and 3-NP treatment models.

Systemic 3-NP treatment via osmotic mini-pump $(0.5 \mu \mathrm{L} / \mathrm{h}$ for 7 days $)$ has been shown to increase ROS and weaken motor function in mice. On the other hand, SOD1 overexpression improved total and mitochondrial ROS levels as well as neuronal motor function in the brain in a 3-NP treated SOD1 transgenic mouse model compared to 3-NP treated wild-type mice (Cho et al., 2013). As SOD reduces $\mathrm{O}_{2}{ }^{\bullet}$ levels, this suggests 3-NP treatment may cause increased $\mathrm{O}_{2}{ }^{\bullet}$ production as a factor in downstream cellular injury that can be eased with SOD1 overexpression in the 3-NP HD model.

In support of these findings, Sandhir et al. showed that 3-NP treatment in rats increases mitochondrial swelling, LPO, protein carbonylation, and ROS while simultaneously decreasing mitochondrial and cytochrome activities, glutathione levels, and SOD activity. 
When the 3-NP treated rats were supplemented with curcumin nanoparticles, the authors observed an abrogation of the 3-NP-induced effects. First, the curcumin nanoparticles revived mitochondrial activity and diminished mitochondrial swelling. The supplementation also reestablished glutathione and SOD activities, both of which resulted in a reduction of LPO, protein carbonylation, and ROS. To hypothesize the underlying mechanism of action for curcumin in the context of $\mathrm{HD}$, curcumin can function within the Nrf2 pathway, although further studies are needed to determine a Nrf2-specific contribution to HD neurodegeneration due to its interdependence with OS (Sandhir et al., 2014). Similar results were also seen in a study performed by Rodriguez et al. using a one-month old C57B1/6 mouse model. 3-NP treatment in these mice not only significantly increased LPO but also apoptosis, illustrated by elevated caspase-3 activity and TUNEL staining compared to untreated controls. 3-NP treated mice also exhibited reduced neuronal antioxidant levels such as CAT or GPx consistent with the increase in apoptosis (Rodriguez et al., 2010). The mechanisms by which 3-NP treatment causes OS and consequent changes in cellular processes remains unclear, but the central role for OS-dependent damage in the 3-NP HD model is evident.

In an earlier study by Silva-Adaya et al., brain synaptosomal fractions were isolated from male Wistar rats chronically treated with 3-NP and/or QUIN. Single and combination treatments immediately elevated ROS, leading to LPO and 3-NP-dependent degeneration of the striatum, cortex, and hippocampus or QUIN-dependent striatal immunoreactivity. Supplementation with the antioxidant L-carnitine (Lcar) alleviated all of the 3-NP and QUIN-induced effects (Silva-Adaya et al., 2008). The important caveat for this study is the authors did not examine whether the relief from Lcar supplementation was related to its ability to aid in fatty acid transport to stimulate fatty acid $\beta$-oxidation and metabolism or specific to shifts in ROS due to the 3-NP or QUIN treatments (Silva-Adaya et al., 2008). The latter hypothesis, a shift toward a prooxidative and/or pro-nitrative environment, is supported by these recent reviews investigating OS in HD patients where not only do HD patient brains exhibit higher levels of OS (Browne et al., 1999, Stoy et al., 2005) but also the finding that increased formation of the OS product MDA shows a positive correlation with HD severity (Chen et al., 2007). These data indicate a potential mechanism in HD by which 3-NP induces OS mediated by LPO and ROS to cause neurotoxicity.

Taken together, these studies show that either supplementation by antioxidants or overexpression of enzymes with antioxidant activities singlehandedly or in combination can improve OS effects in HD animal models. Importantly, these studies did not assess whether the presence of $\mathrm{mHtt}$ protein had any additional modulatory effects in the presence or absence of any treatment examined or vice versa. In future studies it is paramount to compare and contrast OS-dependent changes between treatment-induced and genetic HD models for $\mathrm{Htt}$ and $\mathrm{mHtt}$.

Alzheimer's Disease (AD)_Alzheimer's disease is a progressive neurodegenerative disease. The major pathological hypothesis begins with the processing of the Alzheimer's precursor protein (APP). The postulated mechanism starts with processing activity dominated by either $\alpha$-secretases or both $\beta$ - and $\gamma$-secretases cleaving APP. $\beta$ - and $\gamma$ secretase-dependent cleavage of APP leads to the formation of toxic extracellular amyloid $\beta$ 
(A $\beta$ ) peptide fragments. Importantly, overexpression of APP has been shown to promote A $\beta$ fragment production (Kamenetz et al., 2003, Ting et al., 2007), suggesting a saturable threshold for non-toxic $\alpha$-secretase activity in APP processing. A $\beta$ fragments accumulate in the extracellular space until an initial nucleation event occurs. Nucleation causes cooperative aggregation and deposition of $\beta$-amyloid plaques comprised of the toxic $A \beta$ fragments.

Additionally, it is thought that $\mathrm{A} \beta$ fragments potentiate intraneuronal tau hyperphosphorylation, leading to the formation of intracellular neurofibrillary tangles. Tau is a neuronal protein that organizes microtubules, preserves cell shape, and aids in axonal transport along the microtubule network. However when tau is phosphorylated, tau exhibits a decreased binding affinity for microtubules, which reduces tau's ability to aid in microtubule polymerization. Together the extracellular $A \beta$ plaques and intracellular neurofibrillary tangles instigate cognitive and motor impairment that may result in neuronal and eventually organismal death (Francis et al., 1999). Notably, there have been several studies discussed below that indicate a role for $\mathrm{A} \beta$ peptide-induced $\mathrm{OS}$ in models of $\mathrm{AD}$, proposing the contribution of OS as a direct link to the neurodegeneration.

To determine the relevance of OS and LPO in AD, Greilberger at al. examined the blood of healthy $(n=15)$ and neurodegenerative disease (NDD) patients where the NDD category contained both mildly cognitive-impaired $(n=6)$ and AD patients $(n=10)$. They found significant elevations in MDA, protein carbonylation, and oxidized albumin in NDD patients compared to healthy controls, indicating a link between OS-induced LPO and development of the neurodegenerative state (Greilberger et al., 2008). In an earlier study by Hanson et al. to directly examine how OS products affect the AD state, 24-hour $\mathrm{H}_{2} \mathrm{O}_{2}$ or SIN-1 (an $\mathrm{ONOO}^{-}$donor) treatment of NBP2 murine neuroblastoma cells decreases their viability and induces degeneration, increases APP protein levels (SIN-1 increased APP less dramatically than $\mathrm{H}_{2} \mathrm{O}_{2}$ treatment), and inhibits proteasomal activity. These results suggest APP overexpression causes increased sensitivity to neurotoxins such as $\mathrm{H}_{2} \mathrm{O}_{2}$ and $\mathrm{SIN}-1$. Hence, AD patients with overexpressed APP may be less able to compensate for any flux in redox cycling. It follows that APP accumulation and/or aggregation could potentially mirror the treatment-induced effects. Further, they propose the RNS- and ROS-induced pathways are at least somewhat independent due to SIN-1 exhibiting several different results (e.g. SIN-1 caused less of an increase in APP levels) when compared to $\mathrm{H}_{2} \mathrm{O}_{2}$ treatment (Hanson et al., 2003). Thus, OS products may be accelerating neurodegeneration in AD by APP upregulation.

A recent review by Sultana et al. highlights 4-HNE-modified proteins were shown to be present from mild cognitive impairment, early $\mathrm{AD}$, and late $\mathrm{AD}$. Foremost is the glycolytic enzyme enolase, which is commonly found to be adducted with not only 4-HNE but also carbonylated and nitrated in all three stages of AD (Sultana et al., 2013). Then because OS in the AD brain concentrates to the hippocampal region among others, HO-1 displays elevated 4-HNE adduction in AD brain tissue (Sultana et al., 2013). Not only have ROS and RNS been shown to catalyze neurodegeneration, but the increased presence of LPOmodified proteins in AD patient brains may allow for the development of new biomarkers for $\mathrm{AD}$ and novel targets. 
Poly (ADP-ribose) polymerase-1 (PARP1) overactivation has been similarly implicated in neurodegenerative disease pathology. PARP1 is an enzyme involved in DNA repair and apoptotic cell death. The following data suggests a critical role for PARP1 by its activation under OS in the context of AD where nicotinamide (NA) treatment is used as a PARP1 inhibitor. $A \beta$ peptide injection (bilateral stereotaxic injections into the hippocampal CA3 region) prior to seven days of NA treatment (100 mg/kg; intraperitoneal injections) was performed after which the rats were sacrificed and either the brains were dissected or brain synaptosomes were isolated. $A \beta$ peptide injection followed by NA treatment diminished the $\mathrm{A} \beta$-induced increases in MDA, protein carbonylation, and ROS production in rat brain synaptosomes. NA treatment also rescued the $A \beta$-induced decreases in antioxidant protein levels and activities. Thus, NA presumably lessens OS-dependent PARP activation and consequent apoptosis by increasing antioxidant capacity and rendering the synatopsomes more resistant to OS. Interestingly, the higher dose of NA $(500 \mathrm{mg} / \mathrm{kg})$ slightly increased ROS production compared to $A \beta$ treatment alone (Turunc Bayrakdar et al., 2014). This could occur because disproportionate clearance of ROS may result in an abnormal environment. Accordingly, $\mathrm{A} \beta$ peptides promoted a cytotoxic OS environment by PARP1 activation that was attenuated with NA treatment.

In support of these findings, the following two studies propose mechanisms by which $A \beta$ dependent PARP1 activation contributes to OS. First, a 2005 review indicates that PARP1 overstimulation immediately exhausts cellular pools of NAD (Chiarugi, 2005). The exhaustion of NAD blunts NAD-dependent metabolism and subsequent ATP production, e.g. glycolysis and oxidative phosphorylation; this leads to an energy shortage promoting the NAD salvage pathway to increase NAD bioavailability via ATP hydrolysis and ending in cell death (Chiarugi, 2005). Second, more recent research indicates sustained PARP1 activation may be involved in post-translational modifications of mitochondrial electron transport system complex proteins where the mechanism for this remains unclear (Strosznajder et al., 2012). Altogether, PARP1 overstimulation, provoked by conditions such as excessive NO production or availability or any environments which promote DNA damage (Pieper et al., 1999), causes OS to elicit neurotoxicity. Further research into the link between PARP1, LPO, and AD or possibly any neurodegenerative state with an aggregated intermediate may reveal novel therapies targeted at PARP1 inhibition.

OS conditions can stimulate $\mathrm{ONOO}^{-}$production where $\mathrm{ONOO}^{-}$is a possible negative mediator for choline bioavailability, which affects ACh synthesis and hence can be detrimental to neuronal signal transmission, health, and survival. Neuronal death in AD is associated with progressive reductions in the neurotransmitter ACh (Francis et al., 1999) as well as the ACh precursor acetyl-CoA (Szutowicz et al., 2013). Current AD treatments include inhibitors of ACh degradation enzymes, or acetylcholinesterases (AChE) (Tabet, 2006). Research performed by Cuddy et al. showed that SIN-1 blocked high affinity sodiumcoupled choline transporter (CHT) function by a post-translational modification by $\mathrm{ONOO}^{-}$ that potentiated $\mathrm{CHT}$ internalization from the plasma membrane. CHT internalization limits the importation of choline within the SH-SY5Y neuroblastoma model cells. Decreased quantities of choline causes diminished ACh synthesis in the presence of OS. This study identified the upstream OS product $\mathrm{ONOO}^{-}$as a contributor of ACh deficiency. Taken together, this review proposes the efficacy of a possible combination treatment with an 
$\mathrm{ONOO}^{-}$scavenger and an $\mathrm{AChE}$ inhibitor for $\mathrm{AD}$ patients. The proposed benefit of the addition of an $\mathrm{ONOO}^{-}$scavenger not only preventing the degradation of $\mathrm{ACh}$ but also maintaining the pool of ACh synthesis substrates may be important in halting neurodegeneration.

In conclusion, $\mathrm{AD}$ initiates an OS environment by APP upregulation and/or $\mathrm{A} \beta$ aggregation that induces LPO and its end products to be produced. These products then stimulate neurodegeneration by further potentiating APP expression, causing sustained PARP1 activation, reducing antioxidant capacity within brain cells, and limiting choline bioavailability for downstream ACh synthesis. All of these effects maintain a neurotoxic state that promotes neuronal death and declining cognition where the intermediate stage requires $\mathrm{OS}$ and downstream $\mathrm{LPO}$ in $\mathrm{AD}$.

Parkinson's disease (PD)—Parkinson's disease is a progressive nervous system disorder with a typical first symptom of involuntary trembling while at rest and later symptoms of mental and emotional impairment. PD affects several areas of the brain, primarily the substantia nigra, which maintains movement and balance. As PD causes deterioration in the brain, Lewy bodies accumulate in areas of dopaminergic neuron loss. The relationship between PD and Lewy body accumulation remains unclear as to whether they are a byproduct or an active player in PD pathology. Monogenic PD is associated with Park1, 2, 6,7 , and 8 mutations. One of the familial forms of PD stems from loss of function mutations in the parkin protein encoded by Park2. Parkin assembles in a ubiquitin ligase multi-protein complex that functions in the proteasomal degradation pathway (Thomas and Beal, 2007). Parkin modifications linked to OS are hypothesized to contribute to PD. It has been further hypothesized that ROS/RNS contribute to PD development.

Methamphetamine (MA) abuse can increase the risk for PD by inducing LPO and 4-HNE production. MA-induced 4-HNE adduction to parkin causes a parkin insufficiency in rat brain synaptosomes where damaged parkin undergoes degradation via the proteasome (Moszczynska and Yamamoto, 2011). This limits ubiquitin ligase complex assembly, decreases proteasomal catabolism, and causes damaged parkin and proteins to build up in the cell, ultimately leading to neurotoxicity and dopaminergic cell death. Further, intraperitoneal MA treatment $(10 \mathrm{mg} / \mathrm{kg}$ once every $2 \mathrm{~h}$ for $8 \mathrm{~h})$ corresponds to a decline in DA and its metabolites in the striatum. All of these MA-dependent effects were attenuated with intraperitoneal pre-treatment of vitamin $\mathrm{E}(20 \mathrm{mg} / \mathrm{kg}$ once a day for four days prior to any MA treatment and administered every half hour before all MA injections). This study neglected to address, however, the possible cooperation between parkin and the 26S proteasome (Moszczynska and Yamamoto, 2011). Moreover, RNS can mediate parkin SNO and inhibit parkin function in a similar manner to 4-HNE adduction. Parkin SNO was present not only in vitro using HEK293T cells treated with "NO donors, but also in 1methyl-4-phenyl-1,2,3,6-tetrahydropyridine (MPTP)-treated whole brain samples in mice and untreated PD patient brain tissue $(\mathrm{n}=11)$, suggesting a role for RNS in parkin-mediated development of PD (Chung et al., 2004). Another study in SH-SY5Y cells revealed critical cysteine residues that converge on the RING domain of parkin that, when modified by DA, $\mathrm{H}_{2} \mathrm{O}_{2}$, or ${ }^{\circledR} \mathrm{NO}$ (or ${ }^{\circ} \mathrm{NO}$ donors), increase parkin insolubility. Several PD stressors change parkin's solubility to favor its aggregation intracellularly. DA specifically affects parkin 
insolubility, but not other RING-containing enzymes, by covalent modification of parkin's cysteine residues within and surrounding the RING domain compared to control treatment whereas other stressors such as $\mathrm{H}_{2} \mathrm{O}_{2}$ resulted in a non-specific increase in insolubility of both parkin and other RING-containing enzymes with active site cysteine residues. DA uniquely causes higher parkin insolubility than other RING-containing enzymes to accelerate parkin accumulation. This suggests shifts in the redox environment either alone or more specifically as a result of DA metabolism can increase the risk or progression of PD (Wong et al., 2007).

Treatment with MA relocates DA from the extracellular striatal space to the cytosol where DA accumulates and favors its oxidation into DQ and ROS. Shivalingappa et al. found that MA treatment in N27 cells induces formation of 3-NT and 4-HNE in a DA-dependent mechanism at least partially attributed to MA's concurrent reduction in GSH levels relative to untreated controls. They additionally propose 3-NT may correspond to a prior increase in $\mathrm{ONOO}^{-}$where $\mathrm{ONOO}^{-}$can inhibit the DA transporter (Chandramani Shivalingappa et al., 2012). Supplementation with the antioxidant $\mathrm{N}$-acetylcysteine (NAC) restored LPO product and antioxidant levels compared to untreated controls. Antioxidant treatment provides a protective effect in the brain of MA-induced PD models. Further studies are needed to delineate any relationship between $\mathrm{ONOO}^{-}$and 3-NT for their effects on accelerating neuronal death.

In an earlier 2011 study, prophylactic isotopic reinforcement of PUFAs, accomplished by treating mice with PUFAs deuterated at the susceptible bisallylic sites (D-PUFA), led to stabilized sensitivity to OS in a MPTP-induced PD mouse model. First, deuteration prevented ROS-induced activation of PUFA-dependent signaling pathways by inhibiting lipid modifications due to oxidative or nitrative stressors. For instance, the essential early oxidation- and nitration-targeted lipids such as linoleic acid are highly abundant in the mitochondrial membrane suggesting this subcellular environment as one of interest for further research regarding this treatment. Secondly, D-PUFA attenuated the seventy-eight percent drop in DA levels seen with PUFA treatment alone to forty-six percent in D-PUFA treated mice to further implicate a critical role for DA bioavailability in neurodegeneration (Shchepinov et al., 2011). Prevention of lipid modification from OS thus stabilizes the DA concentration in MPTP-induced PD in mice where this links lipid redox signaling to the DA pathway.

Additionally, mitochondrial activity can be disrupted under OS in PD. Hu et al. examined hydrogen sulfide $\left(\mathrm{H}_{2} \mathrm{~S}\right)$ treatment in two PD models, 6-hydroxydopamine (6-OHDA) and rotenone (Rot). $\mathrm{H}_{2} \mathrm{~S}$ is a naturally occurring product of three enzymes that use cysteine as a substrate: 3-mercaptopyruvate sulfurtransferase (mitochondrial and cytosolic), cystathionine beta synthase (cytosolic; major source for $\mathrm{H}_{2} \mathrm{~S}$ in the brain), and cytathionase (cytosolic) (Kamoun, 2004). 6-OHDA and Rot cause OS as a neurotoxin or by inhibition of Complex I in the mitochondrial electron transport chain, respectively. The results specify $\mathrm{H}_{2} \mathrm{~S}$ treatment in rats rescues 6-OHDA-induced neuronal damage in a NOX-dependent manner by suppressing gp91phox upregulation. $\mathrm{H}_{2} \mathrm{~S}$ also rescued 6-OHDA-induced hyperoxia, neuron loss, MDA production, p47phox translocation, ERK1/2 activation, and upregulated ED-1 expression. $\mathrm{H}_{2} \mathrm{~S}$ treatment in both models inhibits pro-inflammatory mediator release such 
as NOX and TNFa (Hu et al., 2010). Not only does this study identify NOX as an upstream instigator resulting from 6-OHDA treatment in the OS environment as critical in neurodegenerative states but also shows that endogenously produced molecules such as $\mathrm{H}_{2} \mathrm{~S}$ may alleviate these signaling pathways in a protective fashion.

Likewise, OS as discussed briefly in the introduction can provide a signal which sustains glial activation and is dominant in neurodegenerative diseases. Normal glial activation contributes to OS through ROS production. Conversely, aberrant, prolonged glial activation surpasses the protective threshold and becomes damaging in an environment lacking the ability for proper signaling to inactivate glial cells. Specifically, the astrocyte and oligodendrocyte populations in the brain contain an inducible lipocalin, ApoD. ApoD secretion induced by aging, injury, or OS in neurodegeneration can mediate protective effects and contribute to increased longevity where its exact mechanisms are still unclear. Research performed by Bajo-Graneras et al. used paraquat (PQ) treatment over five weeks to irreversibly model PD in the astrocytes of either C57B1/6 wild-type mice or one of two models, ApoD homozygous dominant (+/+) or null (-/-) mouse models (Bajo-Graneras et al., 2011). ApoD deficient-derived astrocyte cells displayed reduced survival, continued OS due to decreasing antioxidant levels, and increased basal LPO levels relative to wild-type cells. Exogenous ApoD supplementation increases survival in PQ-treated cells but does not affect the survival of untreated wild-type cells, suggesting an OS-dependent environment for the protective effects of ApoD. The authors propose that ApoD induction is a downstream target of JNK signaling. Importantly, excessive ${ }^{-N O}$ production may stimulate downregulation of $\mathrm{ApoD}$ as ${ }^{\circ} \mathrm{NO}$ only transiently upregulates JNK signaling. A caveat is $\mathrm{ApoD}$ is not the only contributor to the glial activation switch. These authors implicate a more complex signaling system involving ApoE and lipocalin-2 where a study comprised of all of these mediators may be required to fully elucidate the mechanisms at play for astrocyte reactivity in PD and further extrapolate these mechanisms to other neurodegenerative diseases where glial activation is a main concern (Bajo-Graneras et al., 2011). However, as will be discussed later, astrocyte reactivity may not present a critical switch between neuroprotection and neurodegeneration in the same manner as MGLA.

Furthermore, an alternate study carried out by Ganfornina et al. found a significant inverse relationship between LPO and ApoD for acute and low-dose chronic PQ treatment. PQ as an inducer of OS gives rise to LPO product formation in ApoD-null mice when compared to wild-type animals. The increase in the LPO:ApoD ratio negatively correlates to organism survival time, linking LPO to mortality (Ganfornina et al., 2008). However, they neglected to assess brain function, which may have indicated a decline in nerve function prior to death. Such an assessment may strengthen their final model. A general consideration that may be important for the aforementioned ApoD-null animal models is whether the validated results stem from neuronal or global ApoD deficiency. This can be determined using spatial gene engineering to allow for tissue-specific inhibition of gene expression for a gene of interest accomplished for instance through a tetracycline-inducible Cre recombinase system.

On the other hand, MGLA is hypothesized to produce ROS to incite OS in PD. Using lipopolysaccharide (LPS) to activate microglia in rats and stimulate a pro-inflammatory environment, Chung et al. investigated the role of selective serotonin reuptake inhibitors 
(SSRIs) in anti-inflammatory signaling with respect to contributions of NOX and iNOS and their potential roles in neurotoxicity. A specific SSRI, fluoxetine (Prozac), not only preserved normal neuronal morphology compared to LPS-treated rats but also significantly reduced MGLA, oxidant production, protein carbonylation, p67phox membrane translocation (required for NOX activity), and iNOS protein expression (Chung et al., 2010). SSRIs may serve as an untapped resource for research into the roles of NOX and iNOS in other systems and for novel therapies in neurodegenerative conditions where it is important to define the impact and mechanism of MGLA.

To address protein modifications in PD, SNO of X-linked inhibitors of apoptosis (XIAP) may play an important role in how unchecked increases in ${ }^{\circ} \mathrm{NO}$ levels can cause decreased survival of neurons. XIAP proteins bind and sequester caspases to inhibit initiation of apoptosis. Tsang et al. reported that MPTP treatment increases XIAP SNO, where XIAP SNO is also present in post-mortem PD brain tissue (Tsang et al., 2009). Additionally, XIAP-transfected HEK293 cells yield a caspase-3-dependent resistance as a pro-survival mechanism to insult-induced damage from insults such as Rot or DA in neurons. This resistance is abolished upon pre-treatment with ${ }^{\circ} \mathrm{NO}$ donor NOC18 because the bioavailability of ${ }^{\circ} \mathrm{NO}$ modulates SNO of XIAP. When XIAP is S-nitrosylated, the survival of dopaminergic neurons is severely compromised in a PD model. The nitric oxide-linked pro-apoptotic effect is absent when treated with an nNOS inhibitor or the antioxidant ascorbic acid (Tsang et al., 2009). This study highlights the role for ${ }^{\circ} \mathrm{NO}-$ dependent protein post-translational modifications in dopaminergic neurons specifically where a role for DA downstream of increases in ${ }^{\circ} \mathrm{NO}$ may be equally as telling.

In sum, PD progression can not only be affected by alterations in parkin solubility and DA transport and metabolism but also PUFA oxidation, inducible endogenous mechanisms, exogenous treatments for neuroprotection, and protein SNO. To more fully understand the complexities at work, however, it will be important to study the differences among treatment-induced and genetic PD models to compare neurodegeneration-dependent prooxidation and pro-nitration environments to a healthy model. Following this, researchers can establish the specific roles of each mediator as they interplay with one another within the confines of such a complicated, multi-level disease mechanism.

Multiple Sclerosis (MS)-Multiple sclerosis (MS) is a chronic, inflammatory autoimmune disease where endogenous antibodies attack the CNS. The end result of this attack is neuronal demyelination, which is the removal or degradation of the protective myelin sheath surrounding axons. On neurons, the myelinated axons are interspersed with short, unmyelinated regions called nodes of Ranvier, which are distinct not only by the absence of myelin but also the abundance of transmembrane ion channels. Myelin's insulating ability stems from its concomitant lack of ion channels. Myelin prevents sodium and potassium leakage until reaching a node of Ranvier. At the nodes, ions traverse the membrane resulting in transmission of the original action potential down neurons. This is critical because neurons function on an all or none threshold requiring a minimum level of ion flux to cause local depolarization for successive neuronal firing in signal conduction. When local myelin degrades to eventually form lesions or plaques, the neuronal signals at the nodes are disrupted due to decreased efficiency of the conductivity of ions from signal 
initiation to the site of action. This manifests in humans as a deteriorating state with myriad signs and symptoms depending on which neurons are affected and the degree to which damage occurs. Typically, MS patients exhibit diminished coordination, vision, and speech.

When demyelination occurs, neurons are left bare and susceptible to ROS/RNS attack, which directly correlates to a lesion's activity or stage of development. Haider et al. examined the link between OS, mitochondrial injury, and disease progression in brain tissue of MS patients by assessing normal-appearing white matter compared to inactive, slowly expanding, or active lesions. The results show the presence of oxidized phospholipids, MDA, and a progressive increase in the concentration of oxidized DNA from inactive to slowly expanding to active lesion centers (Haider et al., 2011). These markers also appear more frequently in acute or hypoxic rather than progressive or normoxic lesions, respectively, suggesting more aggressive and/or less oxygenated brain tissue is affected with rapid, deleterious results. Interestingly, they found significant increases in expression of APP in active lesions relative to normal-appearing white matter later confirmed in a 2014 study (Haider et al., 2011, David and Tayebi, 2014). Whether this change in APP has any direct relation to the development of MS remains unclear. This may further be complicated by extracellular iron accumulation upon demyelination and consequential upregulation of iNOS in activated microglia (Haider et al., 2014). MS patients exhibit increased OS products in a manner depending on the aggression and severity of the lesions that seemed to correlate to APP upregulation. It may be possible that MS has a similar underlying mechanism for development of neurodegeneration to that seen in $\mathrm{PD}$ and $\mathrm{AD}$ where prevention of protein accumulation and LPO products will hinder CNS deterioration.

To begin tackling the issue of cause and effect, Rejdak et al. have previously shown that the cerebrospinal fluid (CSF) of MS patients had significantly higher ${ }^{\circ} \mathrm{NO}$ metabolites compared to healthy controls and correlated to disease progression (Rejdak et al., 2004). To investigate the significance of iNOS-derived ${ }^{\circ} \mathrm{NO}$ in MS patients, Rejdak et al. compared tissue from relapse-remitting MS patients ( $\mathrm{n}=34)$ to healthy controls $(\mathrm{n}=12)$ using ferritin as a marker for MGLA and neurofilament heavy chain [NfH (Sm135)] as a biomarker for axonal degeneration. The results indicate a three-fold increase in ${ }^{\circ} \mathrm{NO}$ metabolites and an increase in NfH in the CSF of MS patients, which significantly correlates to MS-dependent neurodeterioration. MGLA via the ferritin marker showed no significant change (Rejdak et al., 2008). These results suggest that excessive "NO production rather than MGLA is an important contributor to MS-linked neurodegeneration. A disadvantage, however, was that the study was not longitudinal, i.e. lacking a time course format. Additionally, they did not employ imaging methods for alternate confirmation of neurodegeneration. There is further work to be done to determine the mechanism by which ${ }^{\circ} \mathrm{NO}$ production is initiated in the MS disease model. That determination will aid in elucidating whether modifying any part of that mechanism can ameliorate the effects of excessive ${ }^{\circ} \mathrm{NO}$ production.

In conclusion, it will be of great interest to determine any links between ${ }^{\circ} \mathrm{NO}$ and its downstream metabolites, OS marker accumulation such as MDA or oxidized DNA, and increased APP expression in the development of MS in human patients. The caveat for MS studies like many neurodegenerative diseases lies in the complexity of the disease etiology where having one general animal model may be insufficient to accurately grasp the complete 
MS spectrum as it manifests in humans. For MS studies using animal models, it will be critical to establish a multiple-model approach to research where these findings are confirmed simultaneously in several models and applied across the board (Denic et al., 2011). The opposite, however, may also be true where it is possible that MS exists as subtypes similar to cancer where progression may be demarcated by a different array of signs and symptoms recapitulated within specific models and not others.

Epilepsy and Seizures-Epilepsy and seizures form another facet of research which may yield pertinent knowledge concerning OS in neurodegenerative diseases. Epilepsy is a condition marked by spontaneous, recurring seizures. Modeling epilepsy in vivo requires genetically engineered animals exhibiting this phenotype. Isolated seizures can be modeled with treatment-induced states and are not limited to the recurring phenotype of in vivo models. A more in-depth review of epilepsy and seizure animal models can be found here (Loscher, 2011). Seizures are characterized by a sudden onset of electrical activity in neurons and subsequent ROS production. Seizures can result from one or more of the following: low blood gases $\left(\mathrm{CO}_{2}\right.$ or $\left.\mathrm{O}_{2}\right)$, brain infection, metabolic abnormalities, injury, fever, edema, drugs, or a pre-existing condition causing any of the other stimuli listed. The overlapping use of KA as a glutamate analog and excitotoxic agent is not only for inducing seizures but also used as an HD model. Pilocarpine (PIC) is another commonly utilized excitotoxic seizure inducer.

According to the following study, OS from seizures can predispose neurons to damage or death. In a female mouse model, KA treatment induced oxidative damage in hippocampal CA1 pyramidal neurons marked by shortened dendrite length and dendrite spine density but elevated NOS activity and LPO. Antioxidant or non-steroidal anti-inflammatory treatment, vitamin E or Ibuprofen, respectively, alleviated these KA-induced effects (Zaja-Milatovic et al., 2008). KA-induced seizures cause OS-dependent damage through a LPO mechanism among others that may exist concurrently.

A study by Shin et al. then associated LPO to neuron death following KA treatment. KAinduced excitotoxicity in rats leads to immediate (4h) increases in OS-linked LPO product formation. LPO formation positively correlated to neuron loss by 48 hours. Each of these parameters, i.e. MDA, protein carbonylation, and GSH:GSSG, were potentiated in genetically epileptic-prone (GEPRs) and/or aged rats relative to control Sprague-Dawley and/or young rats. Based on previous findings that intravenous GSH treatment counterbalances KA-associated neurotoxicity, they showed an imbalance in the GSH:GSSG ratio in GEPRs, which may impede the antioxidant response system resulting in greater OS and more extensive neuronal cell death (Shin et al., 2008b). Seizures thus increase OS via LPO production. In a later study, LA supplementation is used as an antioxidant and mitochondrial cofactor to improve pilocarpine (PIC)-induced seizure effects in the brain's striatum. LA pre-treatment thirty minutes prior to PIC treatment reduces LPO and nitrite levels while simultaneously increasing SOD, CAT, and GPx activities. PIC treatment alone also showed significantly increased GPx activity compared to control, yet LA administration prior to PIC treatment potentiated the increase in GPx activity significantly compared to PIC alone and controls (these changes were independent of protein expression levels). Thus, PIC treatment supplemented with LA conferred a $65 \%$ decrease in seizures and a $30 \%$ increase 
in survival compared to PIC-only treated rats (Militao et al., 2010). These studies add support to an underlying role for OS in seizures. LPO mediates OS where antioxidant treatment may be a valuable therapy in preventing not only seizures but also the consequent damage. The question then becomes whether or not antioxidant treatment is more beneficial as a prophylactic or post-seizure treatment.

The role for OS, and more specifically lipid redox cycling, was additionally confirmed in the alternate KA-induced seizure model in dissected hippocampi of tenday-old Wistar rats using ApoD treatment as an antioxidant. In the rat hippocampal cell model treated with KA and supplemented with ApoD, He et al. shows ApoD increases neuronal viability in a dosedependent manner due to inhibiting LPO. The authors suggest this may take place because ApoD binds and shields lipids from oxidative attack by sequestering lipids in its hydrophobic binding pocket (He et al., 2009). Antioxidant activity correlates to neuroprotection but also directly shows that susceptible lipid attack in OS conditions is responsible for decreased neuron survival in KA-induced seizures in the hippocampi of rat brains similar to the isotopic PUFA reinforcement study in PD.

Additionally, not only does KA treatment induce OS during seizures, but KA also promotes mitochondrial dysfunction. Shin et al. completed a study using two aged (12 months) genetic mouse models, senescence accelerated prone (SAM-P8) and senescence accelerated resistant (SAM-R1), to determine the role of mitochondria in KA-treated seizures. By isolating mitochondrial extracts from the murine hippocampal region and assessing mitochondrial health, KA treatment was shown to increase caspase-3 and lipofuscin for apoptosis and mitochondrial damage, respectively (Shin et al., 2008a). Further, KA treatment led to decreased mitochondrial membrane potential, MnSOD downregulation, and elevated LPO and protein carbonylation levels, the latter two of which exhibited enrichment in the mitochondrial fraction. Based on these, the authors argue mitochondria mark the areas of greatest oxidative-induced insult from KA treatment in hippocampal cells compared to whole cell homogenate. Specifically, these stress effects were more amplified in the SAMP8 mice compared to resistant, aged-matched controls. Altogether these results imply hippocampal mitochondrial dysfunction as a plausible biomarker for seizure-induced stress and damage exacerbated with aging (Shin et al., 2008a).

Hence, epilepsy and seizures are marked by LPO-dependent neuronal loss and mitochondria-targeted OS that worsened upon aging. It is possible that by determining the mechanism(s) by which OS and LPO increase cell death in a seizure model that those same mechanisms can be shown to account for the OS in neurodegenerative diseases.

Ischemia-Ischemia is a condition in which tissue is inadequately perfused with blood, thus causing a hypoxic environment and subsequent OS. A hypoxic environment will lower oxygen tension and may cause damage in the particularly vulnerable brain regions such as the hippocampus, striatum, and substantia nigra targeted by neurodegenerative diseases. Reperfusion occurs when adequate blood flow to the area is reestablished. Because of the sensitivity to OS in the brain and ischemia-induced hypoxia, it is important to consider research outcomes in the ischemia and reperfusion field as it pertains to the brain. 
Perez-Asensio et al. performed intraluminal right middle cerebral artery occlusion ischemia/ reperfusion (IR) in an in vivo rat model to examine nitrosative stress as it relates to reactive hyperemia, or elevated body temperature following an ischemic event. The data suggest RNS involvement where they hypothesize $\mathrm{ONOO}^{-}$as potentially causative for IR-induced reactive hyperemia, which resulted in a significant increase in 3-NT. Antioxidant treatment with a vitamin E analog, CR-6, reduced these effects (Perez-Asensio et al., 2010). As previously discussed, $\mathrm{ONOO}^{-}$production depends on the bioavailable pool of $\mathrm{O}_{2}{ }^{\bullet}$ and ${ }^{\circ} \mathrm{NO}$, additionally implicating these ROS/RNS in this mechanism. A criticism of this study is the inability to discount the feasible contribution of COX-2; CR-6 treatment also reduced the IR-dependent upregulation of COX-2 (Perez-Asensio et al., 2010). This drawback may be of significance in that previous studies have concluded that COX-2 inhibition preserves the blood-brain barrier (BBB) and helps thwart leukocyte infiltration (Strauss, 2008). It is of interest to pursue which protein(s) is being targeted for nitration in these conditions, if protein nitration tends to occur in a precise subcellular location, and if the mechanism is COX-2-dependent.

Moreover, minocycline treatment might diminish oligodendrocyte toxicity through a repressive pathway controlling excessive ${ }^{\circ} \mathrm{NO}$ production as a consequence of MGLA. Cai et al. demonstrated a neuroprotective effect of minocycline treatment in ischemia. In a rat model of carotid artery ligation, the "hypoxia/ischemia-induced microglial activation suppressor," or minocycline, is administered before and after ligation (Cai et al., 2006). The data reveal minocycline treatment reduces toxic LPO product formation and ameliorates ischemia-induced hypomyelination of neurons, providing the rationale that minocycline may play a therapeutic neuroprotective role (Cai et al., 2006). This suggests environments with sustained suboptimal oxygen tensions in the brain may initiate demyelination where this may be important in MS among other neurodegenerative conditions.

In line with the previous study, Lopez-Sanchez et al. examined the effect of $\mathrm{ONOO}^{-}$using kaempferol treatment as an $\mathrm{ONOO}^{-}$scavenger in a rat model of transient focal cerebral ischemia. Kaempferol administration not only resulted in less extensive neuron damage but also weakened the significant induction of LPO, 3-NT, and caspase-9 activation (LopezSanchez et al., 2007). This study offers support for $\mathrm{ONOO}^{-}$as a major regulator of injury and neuron loss in ischemia-induced neurodegeneration modulated by its ability for protein nitration.

According to a study from Mohagheghi et al., there may be a sex-specific component of hormonal regulation in OS-induced damage. A rat model of transient global forebrain IR after prior treatment with gemfibrozil illustrates the sex-dependent mechanism.

Interestingly, untreated males showed resistance to IR injury where untreated females showed sensitivity to IR. However, males pre-treated with gemfibrozil before IR displayed neurotoxicity through activation of pro-inflammatory signaling resulting in hippocampal neuron loss. In opposition to this, upon gemfibrozil pre-treatment preceding IR, femalespecific neuroprotection caused activation of antioxidant machinery and decreased MDA levels in a Nrf-2-independent manner. Because the hypolipidemic fibrate, gemfibrozil, is typically prescribed as a cardiovascular prophylactic, researchers must investigate further as to how gemfibrozil may be beneficial in a sexually dimorphic mechanism (Mohagheghi et 
al., 2013). A 1996 study did find a correlation between gemfibrozil treatment and increases in adrenal androgens, which may relate to the neurotoxic results seen in males but absent in females (Hautanen et al., 1994). Based upon these findings, further studies will be needed to determine a sex-specific hormonal component for both IR resistance and gemfibrozil treatment as a neuroprotective pre-treatment. There may be a hormonal component to the incidence, development, and progression of neurodegeneration where researchers can determine sex-specific effects within animal models as the brain is an endocrine organ producing hormones in addition to responding to other endocrine signals originating from elsewhere within an organism.

There has been a proposed link between the p75 neurotrophin receptor (p75) and neurodegeneration through modulation of ACh metabolism. While investigating the role of cell-specific expression of p75 in striatal cholinergic neurons in global ischemia, Greferath et al. found cell-specific p75 upregulation delays neuron shrinkage up to post-ischemia day 5. Following the delayed shrinkage, p75 expression caused an elimination of choline acetyltransferase expression resulting in a nearly complete loss of cell viability by postischemia day 8 (Greferath et al., 2002). This data highlights a role for p75 as a modulator of cell death, neurodegeneration, and ACh.

Essentially, these ischemia studies provide critical insight into the primary mechanisms of neurodegeneration including players such as ${ }^{\circ} \mathrm{NO}, \mathrm{ONOO}^{-}, \mathrm{LPO}$ product formation, $\mathrm{p} 75$, and a possible sex-dependent hormonal contribution.

Diabetes and Peripheral Diabetic Neuropathy (PDN)—Diabetes is a non-infectious disease state of which there are two types. This review will focus on Type II non-insulindependent diabetes mellitus (T2NIDDM). T2NIDDM is distinguished by altered insulin responsiveness in target organs. Diabetes is also known to cause nerve disorders referred to as diabetic neuropathies. The prevalence of neuropathies due to diabetes is reported to range from five to seventy percent in diabetic patients where those individuals with nerve damage can be asymptomatic or express a plethora of symptoms. A more detailed dialogue on neuropathies and current therapies can be viewed here (Vinik et al., 2013, Zhou and Zhou, 2014). Because diabetes exists as an independent risk factor for nerve damage, it follows that signaling in diabetes may correlate to and further elucidate the mechanisms by which neurodegeneration is prompted and promulgated. Hormonal control for and regulation of glucose may be an essential switch for nerve health and survival. Insulin signaling is paramount for regulation of cytoprotective genes (Lee et al., 2014) and DA metabolism (Niswender et al., 2011). In a diabetic state, insulin resistance leads to downregulation of genes containing insulin response elements to induce cell death and result in decreased DA levels (Williams et al., 2007). In PDN, ONOO- hastens nerve deterioration (Vareniuk et al., 2009). Insulin and resveratrol treatments have been shown to improve diabetes-induced nervous system effects (Craft et al., 2012, Hurley and Tizabi, 2013, Pallas et al., 2013).

When OS transforms the cellular environment, changes occur in signaling pathways that oppose signaling under normal conditions. Ali et al. examined the role for $\mathrm{ONOO}^{-}$in retinal neurodegeneration caused by diabetes that was experimentally induced by streptozotocin (STZ) in a rat model and also in human retinas. Diabetes induced by STZ treatment is 
associated with significant elevations in 4-HNE and 3-NT in rat and human retinas where 3NT was used as a marker for $\mathrm{ONOO}^{-}$(Ali et al., 2008). 4-HNE and 3-NT then can lead to a specific neuropathy known as diabetic retinopathy and result in neuron death through increases in the RNS, $\mathrm{ONOO}^{-}$. Peroxynitrite in this condition causes nitration of the tropomyosin receptor kinase A (TrkA). TrkA tyrosine nitration blocks nerve growth factor (NGF) from binding its target, p75, and stimulates apoptosis. Thus, the TrkA/NGF/p75 cascade can be a pro-survival neuroprotective or neurotoxic mechanism where TrkA nitration is a switch promoting neuronal death (Ali et al., 2008).

In a more detailed study using $\mathrm{ONOO}^{-}$decomposition catalysts FP15 and FeTMPS, Vareniuk et al. explored PDN in wild-type and leptin-deficient (ob/ob) mice. The results revealed that treatment with a $\mathrm{ONOO}^{-}$decomposition catalyst leads to improvement in nerve response and conduction, PPAR reactivity, and 3-NT production but exhibits no difference in rescuing nerve fiber density loss (Vareniuk et al., 2007). In PDN, RNS-dependent stress does cause deteriorating nerve function and encourages an OS environment but not loss of nerve fibers.

With the implication of $\mathrm{ONOO}^{-}$, it follows to investigate upstream mediators of $\mathrm{ONOO}^{-}$, specifically NOS enzymes, for their roles in diabetes-induced neurodegeneration. The two studies below propose a two-pronged mechanism by which neurodegeneration is caused by iNOS in the peripheral nervous system and by nNOS in the CNS. Whether this is due to the presence of other signaling mediators, NOS tissue-specific protein expression, or the presence of their downstream NOS-specific targets remains unanswered.

First, using a STZ-induced diabetic model (wild-type and iNOS-null mice), Vareniuk et al. hypothesized that iNOS-derived ${ }^{\circ} \mathrm{NO}$ leads to nitrosative stress in diabetic neuropathy. Diabetic mice with wild-type iNOS displayed significant changes in neural conduction (as evidenced by increased withdrawal latencies and reduced tactile responses), reductions in intradermal nerve fiber density, a seventy percent increase in 3-NT in the sciatic nerves, and elevated PPAR immunoreactivity. The increase in 3-NT, however, revealed to be independent of diabetes (Vareniuk et al., 2008). All of the changes were attenuated upon iNOS deficiency in peripheral nerves, not dorsal root ganglion nerves, positing the importance of iNOS in provoking and mediating peripheral nerve damage resulting from diabetes. This suggests the alterations are a consequence of ${ }^{\circ} \mathrm{NO}$, not $\mathrm{ONOO}^{-}$.

Second, using a STZ-induced PDN in vivo mouse model, Vareniuk et al. examined the role of nNOS or its deficiency in wild-type and diabetic mice. Diabetic wild-type mice displayed nitrosative stress whereas diabetic nNOS-null mice stopped diabetes-induced $\mathrm{ONOO}^{-}$injury to dorsal root ganglion nerve cells but not in peripheral nerves (Vareniuk et al., 2009). This defines a role for nNOS-mediated neuroprotection in the central, but not peripheral, nervous system.

For diabetes and its corresponding neuropathies, ${ }^{\circ} \mathrm{NO}$ and $\mathrm{ONOO}^{-}$are placed upon a causative pedestal for the observed nerve damage in a pro-oxidant environment echoed in neurodegenerative disease states. Therapies aimed at NOS inhibition, prevention of ONOO- 
formation, or TrkA nitration could avoid the irreversible nerve damage and pain and/or numbness resulting from the effects of unrelenting OS.

Glaucoma-Glaucoma is an eye-specific neurodegenerative disease marked by retinal ganglion cell loss that results in permanent vision deficits and blindness. Similar to other neurodegenerative diseases, glaucoma has no cure with only supportive care available for slowing the progression of the neuron loss (Gupta and Yucel, 2007). One of the major risk factors for glaucoma is increased intraocular pressure (IOP), which can be exacerbated by a systemic hypertensive state.

However, recent glaucoma research lays the groundwork to reveal a dependence on and neurotoxicity during OS and LPO product formation as well as their downstream effects in the DBA/2J mouse model. Thus, Inman et al. set out to elucidate the role for OS in DBA/2J mice employing a-lipoic acid (ALA) treatment as an endogenously synthesized antioxidant that can also be ingested in the diet. They demonstrated that ALA treatment both restored glaucoma-induced reductions in antioxidant expression and increases in LPO, 3-NT, and DNA oxidation. The OS changes were concurrent with increases in IOP in the untreated glaucoma mouse where, interestingly, ALA treatment did not affect IOP. ALA treatment did maintain ganglion cell number compared to untreated mice independent of IOP (Inman et al., 2013). Hence, ALA treatment in this model is neuroprotective in the eye's retinal ganglion cells. In brief, glaucoma as a neurodegenerative condition classically characterized by changes in IOP may actually be at least partially caused by OS-specific changes in the cellular environment deleterious to nerve cells.

Lysosomal Storage Diseases (LYSD)—Lysosomal storage diseases are a heterogeneous category characterized by the effects of undigested or partially catabolized macromolecules that accumulate and cause disruption of the normal cellular environment. These are relevant in the context of OS and lipid redox cycling due to consequent protein and lipid modifications to perturb the normal cellular degradation pathway.

Autophagy via its requirement for lysosomes can be affected by OS conditions. Briefly, the process of autophagy begins when a phagophore assembles to engulf the cargo and elongate into an autophagosome. The autophagosome fuses with a lysosome, yielding an autolysosome. The process of autophagy is under negative control by the mTOR multiprotein complex made up of Raptor, $\mathrm{G}_{\beta} \mathrm{L}$, Deptor, and PRAS40 proteins but has also been shown to be regulated by $\mathrm{O}_{2}{ }^{\bullet}$ (Korolchuk and Rubinsztein, 2011, Szumiel, 2011). However, excessive ${ }^{\circ} \mathrm{NO}$ is proposed to cause neurodegeneration, but its role in autophagy is vague. Analyzing the function of ${ }^{\circ} \mathrm{NO}$ in autophagy, Sarkar et al. illustrated that ${ }^{\circ} \mathrm{NO}$ impairs autophagy via JNK1 and $\mathrm{IKK}_{\beta}$ SNO to activate mTOR signaling. This limits the cell's ability to regulate waste products whose accumulation may be detrimental to cell health and viability (Sarkar et al., 2011). Previously it was stated that ApoD induction is JNKdependent. Not only does superfluous ${ }^{\circledR} \mathrm{NO}$ downregulate ApoD but also activates the mTOR pathway to restrict or completely inhibit autophagic processes. More important is that excess ${ }^{\circ} \mathrm{NO}$ causes these effects on the whole cell, which is not only apt for determining novel targets in neurodegenerative diseases but also on a more generalized level for any process involving ${ }^{\circ} \mathrm{NO}$. 
However, the LYSD mucopolysaccharoidosis IIIB (MPS), also known as Sanfilippo B syndrome, is an autosomally recessive inherited disease identified by mutations in four of the genes that encode enzymes involved in glycosaminoglycan, or heparan sulfate, catabolism. These mutations reduce or abolish enzymatic activity, causing heparan sulfate build-up in cells, namely within lysosomes, and subsequently cause cytotoxicity. Generally MPS patients exhibit blindness and profound nerve atrophy as a result. To clarify the contribution of $\mathrm{O}_{2}{ }^{\bullet}$ in MPS, Villani et al. used the MPS IIIB mouse model. They observed widespread $\mathrm{O}_{2}{ }^{\bullet}$ production, specifically enriched in the rostral region of the cerebrum, and elevated protein carbonylation and LPO in both the cerebrum and cerebellum compared to control. Moreover, SOD1 was downregulated in the rostrum, which may fully explain the $\mathrm{O}_{2}{ }^{\bullet}$ enrichment present within that region. In this MPS IIIB mouse model, $\mathrm{O}_{2}{ }^{\bullet}$ is the primary culprit provoking oxidative damage and cell death due to the impaired degradation of heparan sulfate (Villani et al., 2009). The link between heparan sulfate and $\mathrm{O}_{2}{ }^{\bullet}$ production was further developed by recent work from Trudel et al. whose data show the OS-dependent neurodegeneration seen in MPS IIIB is independent of MGLA and its subsequent proinflammatory signaling activation (Trudel et al., 2014). This is one of the few examples where OS induced nerve damage and loss that was completely unattributed to or involved with MGLA. In MPS IIIB, heparan sulfate accumulation upregulates $\mathrm{O}_{2}{ }^{\bullet}$ production directly to cause nerve damage.

To conclude, there are distinct roles for both oxidative and nitrosative stress in LYSD by affecting lysosomes and autophagy from which cellular damage and death can arise.

Human Immunodeficiency Virus (HIV) - HIV is a retrovirus transferred by exchanges of fluids that eventually develops into acquired immunodeficiency syndrome (AIDS). HIV causes a suppression of the immune system that leaves patients more susceptible to opportunistic infections and cancer. Of interest, HIV causes DA levels to fall and is also associated with neurodegeneration. A study performed by Meulendyke et al. tested the link among HIV, DA, and neurodegeneration in brain striatal tissue using minocycline treatment as an early HIV intervention in a macaque model of simian immunodeficiency virus (SIV). First, the data reveal augmented monoamine oxidase (MAO) activity in both untreated and treated SIV-macaques. MAO is the enzyme responsible for DA conversion to DOPAC, or a DA metabolite, and the side product $\mathrm{H}_{2} \mathrm{O}_{2}$. DA depletion in the striatum and 3-NT formation, however, were significantly greater in untreated compared to minocycline-treated animals. This work suggests then by reducing the oxidative and nitrative stress in SIVmacaques upon minocycline administration, there was a sustained ability to adapt to the DA depletion (Meulendyke et al., 2012). This is presumably through having greater antioxidant capacity to neutralize the $\mathrm{H}_{2} \mathrm{O}_{2}$ produced in treated, but not untreated, SIV-macaques. It is likely the $\mathrm{H}_{2} \mathrm{O}_{2}$ coupled with DA depletion is liable for SIV-associated neurodegeneration.

Sedentary Lifestyles-A sedentary lifestyle is generally defined as time spent in an immobile state such as sitting or lying down. Several recent studies have shown that both a sedentary lifestyle and aging induce OS (Leelarungrayub et al., 2011, Bjork et al., 2012, Rebillard et al., 2013). However, the connection between sedentary lifestyles and neurodegeneration as an effect of OS remains unclear. Using a rat model of daily 
immobilization (6h per day) and administration of the iNOS inhibitor 1400W, Madrigal et al. found that plasma nitrite levels in male rats $(n=8)$ elevated to over $700 \%$ of control by four days and was sustained until the 21 day endpoint of the study. Further, inhibiting iNOSdependent ${ }^{\circ} \mathrm{NO}$ production attenuated the increase in BBB permeability to sucrose in salinetreated sedentary controls. The authors propose a role for ${ }^{\circ} \mathrm{NO}$ in disrupting the homeostasis and protection provided by the BBB (Madrigal et al., 2002). The BBB is crucial for neuronal maintenance and protection whereby ${ }^{\circ} \mathrm{NO}$ 's disruption of the BBB can presumably add further rationale to ${ }^{\circledR} \mathrm{NO}$ 's detrimental function in both aggravating or directly causing neural dysfunction and deterioration.

\section{DISCUSSION}

OS, LPO, and downstream oxidative and nitrative protein/lipid modifications are critical steps in the progression of neurodegenerative diseases and conditions. A profound number of downstream products of OS have been identified within deteriorating conditions in the brain among several in vitro and in vivo models to aid in targeted therapies to attenuate induction of OS products. The initial plan for neurodegenerative diseases involves antioxidant treatment. Antioxidants such as vitamin E (or its most common isoform atocopherol), ALA, and minocycline attenuate OS-induced changes in the brain as described in the preceding sections. Antioxidant treatment has been accepted in the field as supportive care that may temporarily slow or stop progression of neurodegeneration.

However, it remains unclear as to the primary cause(s) of neurodegeneration. Now, it will be vital to attempt a better global understanding of the brain/neuron dysfunction and loss. So elusive questions remain, including (1) is there a common etiology behind OS development in neurodegeneration, (2) is it disease-specific, and (3) can that information be useful in determining a personalized prevention therapy rather than intervention treatment?

Brain cells are already predisposed to OS under normal conditions due to their high energy needs. Several intracellular processes are affected on a global scale upon occurrence of OS (Fig. 4). These include protein folding, mitochondrial dysfunction, excitotoxicity, proteasome-mediated degradation, autophagy, and PARP1 over activation.

-NO inhibits protein folding by the ${ }^{\circ} \mathrm{NO}$-dependent $\mathrm{SNO}$ of protein disulfide isomerase (PDI) at its critical cysteine residues. PDI SNO inhibits the chaperone function of PDI. Brain tissue from AD and PD patients reveal increased PDI SNO compared to control (Uehara et al., 2006). PDI SNO then leads to a rise in misfolded protein aggregation. Because PDI SNO can be aggravated by an "NO donor or blocked with NOS inhibition, it incriminates a NOS-dependent increase in ${ }^{\circ} \mathrm{NO}$ in neurodeteriorative disorders due to the mutual factor of proteinaceous plaque formation frequently found in $\mathrm{AD}, \mathrm{PD}, \mathrm{HD}$, and MS. Interestingly, the ${ }^{\circ} \mathrm{NO}$-induced PDI SNO to total PDI ratio compares to the PDI SNO to total PDI ratios exhibited by other neuronal models where cell death is claimed to result from damaged protein accumulation (Uehara et al., 2006). $\mathrm{NO}$ then links chaperone activity with neurodegeneration. 
In addition to affecting PDI-dependent protein folding, OS can also trigger mitochondrial dysfunction. Thus when OS causes damage to the mitochondria, brain cells are less equipped to mobilize and adapt and therefore are more prone to activate cell death mechanisms. This is because (1) neuronal mitochondria undergo sluggish turnover, (2) neurogenesis in adults is insignificant, and (3) the increased sensitivity for OS leads to cell death in an attempt to localize the cause of downstream mitochondrial damage. The latter demonstrated the possible involvement of Nrf2 signaling activation in the improvement of mitochondrial dysfunction in HD and ischemia studies (Mohagheghi et al., 2013, Sandhir et al., 2014). The activation of cell death may be successful in other tissues such as the skin or gastrointestinal system during OS-induced mitochondrial dysfunction where these cell populations proliferate and replenish their cells within a predictable window of time. Conversely, the intended protective mechanism of neuronal loss does not fix the cause of mitochondrial dysfunction, as neurons generally are irreplaceable in the adult human. OSdependent mitochondrial dysfunction may be a direct cause of neuron loss.

Moreover, OS sensitizes neurons to glutamate-dependent excitotoxicity like what is common in neurodegenerative diseases. Increases in glutamate or other excitatory amino acids alone directly cause cell death. However, in concert with OS, neuronal death increases in a synergistic manner (Kriscenski-Perry et al., 2002). This suggests that any shift toward a pro-oxidant environment, however minimal, may be deleterious in the brain, especially as aging reduces the antioxidant capacity, providing an environment where OS is more likely to be established. Likewise, OS via ${ }^{\circ} \mathrm{NO}$ regulates apoptosis. As discussed previously, ${ }^{\circ} \mathrm{NO}$ causes SNO of XIAP to de-repress apoptosis. Without the equilibrium shift into an ${ }^{\circ} \mathrm{NO}$-rich state, XIAP proteins enable a pro-survival mechanism. SNO disrupts XIAP's ability to bind caspases and inhibit cell death, thus instead favoring cell death.

OS products are similarly involved in the modulation of proteasomal catabolism. $\mathrm{ONOO}^{-}$ and $\mathrm{H}_{2} \mathrm{O}_{2}$ can each inhibit proteasomal activity, which in AD can cause APP accumulation and potentiation of OS and A $\beta$ formation (Prasad et al., 2004). Further, 4-HNE affects proteasomal degradation by covalently adducting to cathepsin $\mathrm{B}$, an integral protein in the degradation pathway (Crabb et al., 2002). In an analogous fashion, autophagy is a target of OS. Specifically discussed were examples showing ${ }^{\circ} \mathrm{NO}$-dependent SNO of JNK1 and IKK ${ }_{\beta}$. JNK1 SNO down regulates Bcl-2 phosphorylation. When Bcl-2 is not phosphorylated, Bcl-2 displays higher affinity for Beclin-1, which inhibits autophagy (Sarkar et al., 2011). As a beneficial endogenous antioxidant, ApoD cannot prevent LPO formation when JNK1 is Snitrosylated (Bajo-Graneras et al., 2011). $\mathrm{IKK}_{\beta}$ SNO down regulates AMPK phosphorylation. The decreased AMPK phosphorylation allows activation of mTOR as a negative regulator of autophagy (Sarkar et al., 2011). Briefly, increases in ${ }^{\circ} \mathrm{NO}$ and ${ }^{\circ} \mathrm{NO}-$ dependent RNS thwart autophagy and promote LPO formation. OS products contribute to regulation of the proteasomal activity and autophagy. An environment supporting formation of OS products simultaneously supports inhibition of normal waste clearance mechanisms within cells. This can lead to cytotoxicity due to the accumulation of molecules targeted for degradation or clearance similar to what is seen when the aforementioned protein folding is affected. 
Lastly, PARP1 over activation has been shown to be deleterious in brain cells. PARP1 overstimulation can be caused by ${ }^{\circ} \mathrm{NO}$, where activated PARP1 upregulates the transcription of pro-inflammatory and immune response target genes (Kim et al., 2005). It is also possible that activated PARP1 functions downstream of $A \beta$ in $A D$ to signal within a pathway that engenders OS and cell death in the brain (Turunc Bayrakdar et al., 2014). Inhibition of PARP1 has also been shown to prevent A $\beta$-dependent MGLA, which in turn prevents neurotoxicity from ROS produced as a result of MGLA (Pieper et al., 1999, Kauppinen et al., 2011). PARP1 activation has recently been implicated in the onset of diabetes-induced retinal neuropathy as well where PARP1 inhibition resulted in neuroprotection (Mohammad et al., 2013). Because of these effects, therapies aimed at PARP1 inhibition are of great interest in neurodegenerative disease states.

There exists a delicate balance of ROS/RNS production and antioxidant to oxidant capacity in the brain. Any shift that promotes an OS environment predisposes cells to any one or several of these events temporarily or permanently (Fig. 4). However, once an OS state induces consequent MGLA, pro-inflammatory cytokine release provokes ROS/RNS production and LPO formation. Activated microglial cells undergo morphological changes and primarily induce iNOS-dependent ${ }^{\circ} \mathrm{NO}$ production. Nitric oxide production upregulates CD11b, an MGLA marker (Roy et al., 2006). By inhibiting cellular respiration, ${ }^{\circ} \mathrm{NO}$ causes glutamate secretion that leads to excitotoxic cell death and secondary activation of $\mathrm{N}$ methyl-D-aspartate receptors (NMDAr). When NMDAr activation takes place, cellular and organelle membranes experience increased calcium permeability which positively stimulates ${ }^{\circ} \mathrm{NO}$ production (Bal-Price and Brown, 2001). The end result is chronic MGLA and an auto-regulated neuroinflammatory positive feedback state (Fig. 3). When this neuroinflammatory state is disrupted with an MGLA inhibitor such as minocycline, neuroprotection is observed due to reduced MGLA and inhibition of iNOS induction. Of note, minocycline did not stop astrocyte activation, suggesting astrogliosis does not precede neuronal death or play as central of a role in OS-dependent neurodegeneration. Minocycline treatment yields attenuation of both DA loss and 3-NT modifications in ischemia (Yrjanheikki et al., 1998) and has provided neuroprotection in AD (Biscaro et al., 2012), MS (Brundula et al., 2002), HD (Ryu et al., 2006), and PD (Du et al., 2001, Wu et al., 2002). These minocycline studies as a treatment highlight the central role of OS-dependent MGLA in neurodegenerative diseases.

Additionally, fluctuation of DA bioavailability and its metabolism have been associated with MGLA, OS, and neurodegeneration. Activated microglia cause the formation of DQ by DA auto oxidation in order to (1) sustain MGLA, (2) down regulate neuroprotective genes, and (3) cause nerve damage (Thomas et al., 2006). OS conditions in the brain promote MGLA, which prompts DA auto oxidation that ends in nerve damage and/or death.

Once DA metabolism is shifted, deleterious downstream effects occur similar to the onset of OS or MGLA. MA-dependent blockage of DA uptake causes the extracellular DA pool to rise and stimulate DQ formation and ROS (Thomas et al., 2008). This would suggest the possibility that flux in the intracellular to extracellular DA ratio is important in MA-induced OS-dependent neuronal death in MA-induced PD. Similarly, DQ were shown to significantly diminish SOD2 activity, causing protein aggregation and mitochondrial 
dysfunction in the intracellular environment (Belluzzi et al., 2012). DQ serve as an alternate mechanism in tandem with OS to affect protein aggregation and mitochondrial dysfunction that when both are present may aggravate their downstream effects such as accelerating neurodegeneration in a potentially sensitizing and synergistic fashion.

In addition to MGLA, OS is associated with DA fluctuation. First, $\mathrm{ONOO}^{-}$or ${ }^{\circ} \mathrm{NO}_{2}$ have been shown to impair DA metabolism through tyrosine hydroxylase (TH) nitration. TH is the rate-limiting enzyme in the DA synthesis pathway. TH nitration of one or more tyrosine residues is sufficient to inactivate $\mathrm{TH}$ catalysis as shown by the decline in DA concentrations when TH nitration occurs (Ara et al., 1998, Park et al., 2003). Overexpression of SOD1, however, does prevent TH nitration supporting the dependence of both $\mathrm{O}_{2}{ }^{--}$and ${ }^{\circ} \mathrm{NO}$ to form $\mathrm{ONOO}^{-}$(Ara et al., 1998). Treatment with an $\mathrm{ONOO}^{-}$ decomposition catalyst, NOS inhibitor, or inducers for $\mathrm{O}_{2}{ }^{--}$-catalyzing enzymes then may rescue TH nitration and restore DA synthesis. Second, microglial DA uptake (or other neurotransmitters except glutamate) represses MGLA whereby reductions in DA can allow MGLA (Farber et al., 2005). DA flux results from enzymatic modifications by ROS/RNS and can promote MGLA.

Not only is OS linked to DA regulation in the brain, but the steady state level of Ach has important implications for DA. Decreases in DA are important for Ach-dependent nerve signaling shown in a C. elegans model (Allen et al., 2011, Suo and Ishiura, 2013).

Donepezil, a piperidine derivative that inhibits the degradation of Ach, or an acetylcholinesterase inhibitor, can preserve Ach and DA levels in the AD model. Not all acetylcholinesterase inhibitors can modulate DA release (Dajas-Bailador et al., 1996, Francis et al., 1999, Zhang et al., 2004). Donepezil treatment rescued deficits in memory in in vivo AD models (Kim et al., 2014). Not only is Ach involved in nerve transmission, but Ach is linked to DA availability. When DA is reduced, Ach-dependent signaling is also weakened. It follows that anything which modulates DA also modulates Ach and directly affects nerve health and viability.

To recap, when the brain is under OS, microglia are activated, which not only provides a mechanism by which to sustain MGLA, it stimulates DQ formation leading to detrimental effects that promote and spread neurodegeneration. The contribution of abnormal glucose metabolism or dysregulation of the hormonal control for glucose within neurodegenerative states is also essential to understand. T2NIDDM is particularly associated with DA, OS, and neurodegeneration seen by diabetes-induced downregulation of insulin target genes complemented by oligodendrocyte and neuron cell death (Lee et al., 2014). Specifically, T2NIDDM alone can modulate DA metabolism. Amphetamine-treated insulin deficient rats demonstrate lazy, compromised DA release rescued by insulin treatment (Williams et al., 2007). MA causes a decline in DA concentration as well as decreased TH and dopamine transporter expression in PD models. Importantly, MA administration leads to MGLA immediately where nerve injury can consequently be seen within one week of the initial MA exposure. The MA-dependent MGLA compares directly with the extent of observed neurotoxicity (Granado et al., 2013). MA treatment similar to amphetamine treatment results in dose-dependent neurotoxicity. Further, iNOS-null mice display resistance to MA-induced dopaminergic nerve damage where ${ }^{\circ} \mathrm{NO}$ or downstream $\mathrm{ONOO}^{-}$can trigger or worsen 
damage (Itzhak et al., 1999). MA-induced PD provides a model where MGLA may be causing the DA decline in an iNOS-dependent mechanism.

AD patients exhibit insulin resistance, or hypoinsulinemia, in the brain manifested by disturbed glucose metabolism, or hypoglycemia, implicating a potential role for modulation of glucose signaling (Chen and Zhong, 2013). Additionally, Sultana et al. concluded that abnormal glucose metabolism represents a link to cognitive impairment associated with the incidence and progression of dementia in AD (Sultana et al., 2013). An earlier study exhibited improvement in cognition and $\mathrm{A} \beta$ levels upon intranasal insulin supplementation in $\mathrm{AD}$ (Craft et al., 2012). It follows that $\mathrm{ONOO}^{-}$production amplifies nerve deterioration in PDN where diabetes was the primary cause of the initial nerve damage (Stavniichuk et al., 2014). These three studies provide evidence that diabetes and consequent RNS production may play a more direct role than simply as a risk factor in OS-induced neurodegeneration.

In a more generalized sense, resveratrol is a polyphenol that has been shown to inhibit glial activation and contribute to neuroprotection through regulation of protein expression and modulation of inflammatory signaling. In astroglial cells, resveratrol treatment induced HO-1 expression and GSH levels to offset ROS-induced astroglial damage (QuincozesSantos et al., 2013). In a STZ-treated rat model of diabetes, resveratrol slowed diabetesinduced neurodegeneration by decreasing both astrocytic activation and secretion of proinflammatory mediators like TNFa in the rat hippocampus (Jing et al., 2013). In another study examining oxidative nerve damage in lean and obese mice, resveratrol blocked the obesity-specific increases in LPO and upregulated antioxidant activity (Rege et al., 2013). Finally, in an earlier study of primary midbrain neuron-glia rat tissue cultures, resveratrol provided dopaminergic neuroprotection by inhibiting MGLA in lipopolysaccharide-induced neurotoxicity (Zhang et al., 2010). Not only does resveratrol provide relief from OS and its downstream products, but it also reduces pro-inflammatory cytokines and prevents MGLA and astrocytic activation. Next, resveratrol was shown to upregulate antioxidants and restore DA levels in a 6-OHDA-induced PD model (Khan et al., 2010). There have been studies on these neuroprotective effects in AD (Rege et al., 2014) and PD (Zahid et al., 2011, Lofrumento et al., 2014, Pangeni et al., 2014). All of these data together form a comprehensive neuroprotective effect concerning DA, diabetes, OS, and MGLA. As a result, resveratrol treatment should be strongly favored as a research tool to determine the underlying step-wise mechanism for onset and progression of neurodegenerative diseases.

To make one last point, p75 is a critical player in the neurodegenerative axis due to its regulation of cell death within the nervous system after injury similar to a second hit p53 mutation in cancer. Activation of p75 has been a critical step in the neurodegeneration seen in AD, amyotropic lateral sclerosis (ALS), MS, and ischemia (Kraemer et al., 2014). 4-HNE production has been shown to activate $\mathrm{p} 75$ via cleavage in a $\gamma$-secretase-dependent fashion to cause nerve deterioration that was absent in p75-deficient mice. This suggests 4-HNE acts as one of several possible upstream mediators of p75 cleavage. Furthermore, p75 upregulation was shown to increase dopaminergic cell death, exacerbating any DAdependent signaling and subsequent damage induced by DA release (Blochl and Sirrenberg, 1996, Kokaia et al., 1998, Turner et al., 2003). Not only is elevated p75 expression or cleavage leading to neurodegeneration within specific models, but modulation of the p75 
pathway as a whole also does as exemplified by TrkA nitration (Ali et al., 2008) and KAinduced p75 upregulation in PD (Wang et al., 2008). The complete p75 signaling pathway then is implicated in neurodegeneration where each step can be mediated by different OS products and modifications.

\section{CONCLUSION}

In conclusion, although progress continues to be made in the field of neurodegenerative disease research many questions remain. The importance of OS in neurodegeneration is well known. Recent reviews hypothesize a role for MGLA in neurodegeneration (Brown and Neher, 2010, Choi et al., 2011, Perry and Holmes, 2014). Others link glucose signaling and diabetes in brain diseases (Skundric and Lisak, 2003, Umegaki, 2012, Duarte et al., 2013). Researchers similarly make the connection between DA and Ach in neurodegeneration (Bisaglia et al., 2014, Friend et al., 2014, Kita et al., 2014). This review proposes a comprehensive hypothesis that, like a regulatory switch, the presence of OS instigates MGLA through fluctuations in redox cycling from which the neuroinflammatory phase arises (Fig. 3). This hypothesis is additionally complicated by the occurrence of diabetes and/or disruption of DA metabolism (Fig. 4). These conditions amplify the basal OS that sustains MGLA leading to brain injury. If, on the other hand, the onset of diabetes or abnormal DA metabolism is the initial stimulus to generate an OS/NS condition, either one can trigger MGLA. MGLA, diabetes, and altered DA metabolism are accordingly interconnected to redox signaling within a chicken-and-egg paradox in neurodegenerative states. The mechanism proposed above is hypothetical and a jumping off point for future research. Nonetheless, all of these processes point to the incidence of an OS/NS environment characterized by ROS/RNS generation where LPO, in addition to other lipid modifications lead to neurodegeneration. Considering these concepts simultaneously, compiled studies comparing treatment-induced models, genetic models, and patient data, allow researchers to deduce the intricacies of OS/NS and redox homeostasis in regulating MGLA, DA, and diabetes associated with neurodegenerative diseases. Because these mechanisms discussed throughout this review are scattered among several studies, it will be of interest to see how continued efforts in these fields will begin to converge their ideas into meta-hypotheses of brain signaling and regulation to determine the primary cause of neurodegeneration as it classically relates to OS/NS and resulting lipid/protein modifications.

\section{ACKNOWLEDGMENTS}

We thank Saad Rahmat and Kellianne Piell for their collegial input and critical reading of the manuscript.

\section{Abbreviations}

$\begin{array}{ll}\text { OS } & \text { Oxidative stress } \\ \mathbf{O}_{4}{ }^{-} & \text {superoxide } \\ { }^{-} \mathrm{NO} & \text { nitric oxide } \\ \cdot \mathrm{OH} & \text { hydroxyl radical }\end{array}$




\begin{tabular}{|c|c|}
\hline ROH & peroxyl radical \\
\hline ONOO- $^{-}$ & peroxynitrite \\
\hline $\mathbf{H}_{2} \mathbf{O}_{2}$ & hydrogen peroxide \\
\hline ROS & reactive oxygen species \\
\hline RNS & reactive nitrogen species \\
\hline XO & xanthine oxidase \\
\hline NOX & NADPH oxidase \\
\hline SOD & superoxide dismutase \\
\hline CAT & catalase \\
\hline GPx & glutathione peroxidase \\
\hline GSH & reduced glutathione \\
\hline GSSG & oxidized glutathione \\
\hline NOS & nitric oxide synthase \\
\hline nNOS & neuronal nitric oxide synthase \\
\hline iNOS & inducible nitric oxide synthase \\
\hline eNOS & endothelial nitric oxide synthase \\
\hline FMN & flavin mononucleotide \\
\hline FAD & flavin adenine dinucleotide \\
\hline $\mathrm{BH}_{4}$ & tetrahydrobiopterin \\
\hline PUFA & polyunsaturated fatty acid \\
\hline LPO & lipid peroxidation \\
\hline 4-HNE & 4-hydroxy-2-nonenal \\
\hline MDA & malondialdehyde \\
\hline TBARS & thiobarbituric acid reacting substance \\
\hline 3-NT & protein tyrosine nitration \\
\hline SNO & S-nitrosylation \\
\hline $\mathrm{NO}_{2}$-FA & nitrated fatty acid \\
\hline HO-1 & heme oxygenase- 1 \\
\hline NF-kB & nuclear factor kappa light chain enhancer of activated B cells \\
\hline PPAR & peroxisome proliferator-activated receptor \\
\hline${ }^{\cdot} \mathrm{NO}_{2}$ & nitrogen dioxide radical \\
\hline $\mathrm{NO}^{+}{ }_{2}$ & nitronium ion \\
\hline
\end{tabular}




$\begin{array}{ll}\text { CNS } & \text { central nervous system } \\ \text { MGLA } & \text { microglial activation } \\ \text { DQ } & \text { dopamine-quinones } \\ \text { DA } & \text { dopamine } \\ \text { ACh } & \text { acetylcholine } \\ \text { T2IDDM } & \text { type II insulin-dependent diabetes mellitus } \\ \text { PDN } & \text { peripheral diabetic neuropathy } \\ \text { HD } & \text { Huntington's disease }\end{array}$

AD

Alzheimer's disease

NDD

neurodegenerative disease

PD

Parkinson's disease

MS

multiple sclerosis

LYSD

lysosomal storage diseases

HIV

human immunodeficiency virus

TBI

traumatic brain injury

Htt

huntingtin protein

mHtt

mutant huntingtin protein

KA

kainic acid

QUIN

quinolinic acid

3-NP

3-nitropropionic acid

Lcar

L-carnitine

APP

Alzheimer's precursor protein

$\mathrm{A} \beta$

toxic amyloid beta peptide fragments

PARP1

poly-ADP-ribose polymerase-1

NA

nicotinamide

AChE

acetylcholinesterases

MA

methamphetamine

NAC

$\mathrm{N}$-acetylcysteine

MPTP

1-methyl-4-phenyl-1,2,3,6-tetrahydropyridine

D-PUFA

deuterated polyunsaturated fatty acid

$\mathrm{H}_{2} \mathrm{~S}$

hydrogen sulfide

6-OHDA

6-hydroxydopamine 


\begin{tabular}{|c|c|}
\hline Rot & rotenone \\
\hline ApoD & apolipoprotein D \\
\hline $\mathbf{P Q}$ & paraquat \\
\hline LPS & lipopolysaccharide \\
\hline SSRI & selective serotonin reuptake inhibitor \\
\hline XIAP & X-linked inhibitors of apoptosis \\
\hline CSF & cerebrospinal fluid \\
\hline NfH [Sm135] & neurofilament heavy chain \\
\hline GEPR & genetically epileptic prone rat \\
\hline $\mathbf{L A}$ & lipoic acid \\
\hline PIC & pilocarpine \\
\hline SAM-P8 & senescence accelerated mouse prone \\
\hline SAM-R1 & senescence accelerated mouse resistant \\
\hline IR & ischemia/reperfusion \\
\hline p75 & p75 neutrotrophin receptor \\
\hline STZ & streptozotocin \\
\hline TrkA & tyrosine kinase receptor A \\
\hline NGF & nerve growth factor \\
\hline ob/ob & leptin-deficient mice \\
\hline IOP & intraocular pressure \\
\hline $\mathbf{A L A}$ & a-lipoic acid \\
\hline MPS & mucopolysaccharoidosis IIIB \\
\hline AIDS & acquired immunodeficiency syndrome \\
\hline SIV & simian immunodeficiency virus \\
\hline MAO & monoamine oxidase \\
\hline BBB & blood brain barrier \\
\hline PDI & protein disulfide isomerase \\
\hline NMDAr & N-methyl-D-aspartate receptor \\
\hline TH & tyrosine hydroxylase \\
\hline ALS & amyotrophic lateral sclerosis \\
\hline
\end{tabular}




\section{REFERENCES}

Ali TK, Matragoon S, Pillai BA, Liou GI, El-Remessy AB. Peroxynitrite mediates retinal neurodegeneration by inhibiting nerve growth factor survival signaling in experimental and human diabetes. Diabetes. 2008; 57:889-898. [PubMed: 18285558]

Allen AT, Maher KN, Wani KA, Betts KE, Chase DL. Coexpressed D1- and D2-like dopamine receptors antagonistically modulate acetylcholine release in Caenorhabditis elegans. Genetics. 2011; 188:579-590. [PubMed: 21515580]

Ara J, Przedborski S, Naini AB, Jackson-Lewis V, Trifiletti RR, Horwitz J, Ischiropoulos H. Inactivation of tyrosine hydroxylase by nitration following exposure to peroxynitrite and 1methyl-4-phenyl-1,2,3,6-tetrahydropyridine (MPTP). Proceedings of the National Academy of Sciences of the United States of America. 1998; 95:7659-7663. [PubMed: 9636206]

Ayala A, Munoz MF, Arguelles S. Lipid peroxidation: production, metabolism, and signaling mechanisms of malondialdehyde and 4-hydroxy-2-nonenal. Oxidative medicine and cellular longevity. 2014; 2014:360438. [PubMed: 24999379]

Bajo-Graneras R, Ganfornina MD, Martin-Tejedor E, Sanchez D. Apolipoprotein D mediates autocrine protection of astrocytes and controls their reactivity level, contributing to the functional maintenance of paraquat-challenged dopaminergic systems. Glia. 2011; 59:1551-1566. [PubMed: 21688324]

Baker LM, Baker PR, Golin-Bisello F, Schopfer FJ, Fink M, Woodcock SR, Branchaud BP, Radi R, Freeman BA. Nitro-fatty acid reaction with glutathione and cysteine. Kinetic analysis of thiol alkylation by a Michael addition reaction. The Journal of biological chemistry. 2007; 282:3108531093. [PubMed: 17720974]

Bal-Price A, Brown GC. Inflammatory neurodegeneration mediated by nitric oxide from activated glia-inhibiting neuronal respiration, causing glutamate release and excitotoxicity. The Journal of neuroscience : the official journal of the Society for Neuroscience. 2001; 21:6480-6491. [PubMed: 11517237]

Belluzzi E, Bisaglia M, Lazzarini E, Tabares LC, Beltramini M, Bubacco L. Human SOD2 modification by dopamine quinones affects enzymatic activity by promoting its aggregation: possible implications for Parkinson's disease. PloS one. 2012; 7:e38026. [PubMed: 22723845]

Bisaglia M, Filograna R, Beltramini M, Bubacco L. Are dopamine derivatives implicated in the pathogenesis of Parkinson's disease? Ageing research reviews. 2014; 13:107-114. [PubMed: 24389159]

Biscaro B, Lindvall O, Tesco G, Ekdahl CT, Nitsch RM. Inhibition of microglial activation protects hippocampal neurogenesis and improves cognitive deficits in a transgenic mouse model for Alzheimer's disease. Neuro-degenerative diseases. 2012; 9:187-198. [PubMed: 22584394]

Bjork L, Jenkins NT, Witkowski S, Hagberg JM. Nitro-oxidative stress biomarkers in active and inactive men. International journal of sports medicine. 2012; 33:279-284. [PubMed: 22377943]

Blochl A, Sirrenberg C. Neurotrophins stimulate the release of dopamine from rat mesencephalic neurons via Trk and p75Lntr receptors. The Journal of biological chemistry. 1996; 271:21100 21107. [PubMed: 8702878]

Bonacci G, Baker PR, Salvatore SR, Shores D, Khoo NK, Koenitzer JR, Vitturi DA, Woodcock SR, Golin-Bisello F, Cole MP, Watkins S, St Croix C, Batthyany CI, Freeman BA, Schopfer FJ. Conjugated linoleic acid is a preferential substrate for fatty acid nitration. The Journal of biological chemistry. 2012; 287:44071-44082. [PubMed: 23144452]

Brown GC, Neher JJ. Inflammatory neurodegeneration and mechanisms of microglial killing of neurons. Molecular neurobiology. 2010; 41:242-247. [PubMed: 20195798]

Browne SE, Ferrante RJ, Beal MF. Oxidative stress in Huntington's disease. Brain pathology (Zurich, Switzerland). 1999; 9:147-163.

Brundula V, Rewcastle NB, Metz LM, Bernard CC, Yong VW. Targeting leukocyte MMPs and transmigration: minocycline as a potential therapy for multiple sclerosis. Brain : a journal of neurology. 2002; 125:1297-1308. [PubMed: 12023318] 
Cai Z, Lin S, Fan LW, Pang Y, Rhodes PG. Minocycline alleviates hypoxic-ischemic injury to developing oligodendrocytes in the neonatal rat brain. Neuroscience. 2006; 137:425-435. [PubMed: 16289838]

Cattaneo E, Zuccato C, Tartari M. Normal huntingtin function: an alternative approach to Huntington's disease. Nature reviews Neuroscience. 2005; 6:919-930. [PubMed: 16288298]

Cepeda C, Cummings DM, Andre VM, Holley SM, Levine MS. Genetic mouse models of Huntington's disease: focus on electrophysiological mechanisms. ASN neuro. 2010; 2:e00033. [PubMed: 20396376]

Chandramani Shivalingappa P, Jin H, Anantharam V, Kanthasamy A, Kanthasamy A. N-Acetyl Cysteine Protects against Methamphetamine-Induced Dopaminergic Neurodegeneration via Modulation of Redox Status and Autophagy in Dopaminergic Cells. Parkinson's disease. 2012; 2012:424285.

Chen CM, Wu YR, Cheng ML, Liu JL, Lee YM, Lee PW, Soong BW, Chiu DT. Increased oxidative damage and mitochondrial abnormalities in the peripheral blood of Huntington's disease patients. Biochemical and biophysical research communications. 2007; 359:335-340. [PubMed: 17543886]

Chen YJ, Ching WC, Lin YP, Chen YJ. Methods for detection and characterization of protein Snitrosylation. Methods (San Diego, Calif). 2013; 62:138-150.

Chen Z, Zhong C. Decoding Alzheimer's disease from perturbed cerebral glucose metabolism: implications for diagnostic and therapeutic strategies. Progress in neurobiology. 2013; 108:21-43. [PubMed: 23850509]

Chiarugi A. Intrinsic mechanisms of poly(ADP-ribose) neurotoxicity: three hypotheses. Neurotoxicology. 2005; 26:847-855. [PubMed: 15923038]

Cho KJ, Kim HW, Cheon SY, Lee JE, Kim GW. Apoptosis signal-regulating kinase-1 aggravates ROS-mediated striatal degeneration in 3-nitropropionic acid-infused mice. Biochemical and biophysical research communications. 2013; 441:280-285. [PubMed: 24021285]

Choi DK, Koppula S, Suk K. Inhibitors of microglial neurotoxicity: focus on natural products. Molecules (Basel, Switzerland). 2011; 16:1021-1043.

Chung ES, Chung YC, Bok E, Baik HH, Park ES, Park JY, Yoon SH, Jin BK. Fluoxetine prevents LPS-induced degeneration of nigral dopaminergic neurons by inhibiting microglia-mediated oxidative stress. Brain research. 2010; 1363:143-150. [PubMed: 20858471]

Chung KK, Thomas B, Li X, Pletnikova O, Troncoso JC, Marsh L, Dawson VL, Dawson TM. Snitrosylation of parkin regulates ubiquitination and compromises parkin's protective function. Science (New York, NY). 2004; 304:1328-1331.

Crabb JW, O'Neil J, Miyagi M, West K, Hoff HF. Hydroxynonenal inactivates cathepsin B by forming Michael adducts with active site residues. Protein science : a publication of the Protein Society. 2002; 11:831-840. [PubMed: 11910026]

Craft S, Baker LD, Montine TJ, Minoshima S, Watson GS, Claxton A, Arbuckle M, Callaghan M, Tsai E, Plymate SR, Green PS, Leverenz J, Cross D, Gerton B. Intranasal insulin therapy for Alzheimer disease and amnestic mild cognitive impairment: a pilot clinical trial. Archives of neurology. 2012; 69:29-38. [PubMed: 21911655]

Dajas-Bailador F, Costa G, Emmett S, Bonilla C, Dajas F. Acetylcholinesterase inhibitors block acetylcholine-evoked release of dopamine in rat striatum, in vivo. Brain research. 1996; 722:1218. [PubMed: 8813345]

Dassati S, Waldner A, Schweigreiter R. Apolipoprotein D takes center stage in the stress response of the aging and degenerative brain. Neurobiology of aging. 2014; 35:1632-1642. [PubMed: 24612673]

David MA, Tayebi M. Detection of protein aggregates in brain and cerebrospinal fluid derived from multiple sclerosis patients. Frontiers in neurology. 2014; 5:251. [PubMed: 25520699]

Denic A, Johnson AJ, Bieber AJ, Warrington AE, Rodriguez M, Pirko I. The relevance of animal models in multiple sclerosis research. Pathophysiology : the official journal of the International Society for Pathophysiology / ISP. 2011; 18:21-29. [PubMed: 20537877]

Du Y, Ma Z, Lin S, Dodel RC, Gao F, Bales KR, Triarhou LC, Chernet E, Perry KW, Nelson DL, Luecke S, Phebus LA, Bymaster FP, Paul SM. Minocycline prevents nigrostriatal dopaminergic neurodegeneration in the MPTP model of Parkinson's disease. Proceedings of the National 
Academy of Sciences of the United States of America. 2001; 98:14669-14674. [PubMed: 11724929]

Duarte AI, Candeias E, Correia SC, Santos RX, Carvalho C, Cardoso S, Placido A, Santos MS, Oliveira CR, Moreira PI. Crosstalk between diabetes and brain: glucagon-like peptide-1 mimetics as a promising therapy against neurodegeneration. Biochimica et biophysica acta. 2013; 1832:527-541. [PubMed: 23314196]

Farber K, Pannasch U, Kettenmann H. Dopamine and noradrenaline control distinct functions in rodent microglial cells. Molecular and cellular neurosciences. 2005; 29:128-138. [PubMed: 15866053]

Fazzari M, Trostchansky A, Schopfer FJ, Salvatore SR, Sanchez-Calvo B, Vitturi D, Valderrama R, Barroso JB, Radi R, Freeman BA, Rubbo H. Olives and olive oil are sources of electrophilic fatty acid nitroalkenes. PloS one. 2014; 9:e84884. [PubMed: 24454759]

Francis PT, Palmer AM, Snape M, Wilcock GK. The cholinergic hypothesis of Alzheimer's disease: a review of progress. Journal of neurology, neurosurgery, and psychiatry. 1999; 66:137-147.

Franco MC, Ye Y, Refakis CA, Feldman JL, Stokes AL, Basso M, Melero Fernandez de Mera RM, Sparrow NA, Calingasan NY, Kiaei M, Rhoads TW, Ma TC, Grumet M, Barnes S, Beal MF, Beckman JS, Mehl R, Estevez AG. Nitration of Hsp90 induces cell death. Proceedings of the National Academy of Sciences of the United States of America. 2013; 110:E1102-1111. [PubMed: 23487751]

Freeman BA, Baker PR, Schopfer FJ, Woodcock SR, Napolitano A, d'Ischia M. Nitro-fatty acid formation and signaling. The Journal of biological chemistry. 2008; 283:15515-15519. [PubMed: 18285326]

Friend DM, Fricks-Gleason AN, Keefe KA. Is there a role for nitric oxide in methamphetamineinduced dopamine terminal degeneration? Neurotoxicity research. 2014; 25:153-160. [PubMed: 23918001]

Ganfornina MD, Do Carmo S, Lora JM, Torres-Schumann S, Vogel M, Allhorn M, Gonzalez C, Bastiani MJ, Rassart E, Sanchez D. Apolipoprotein D is involved in the mechanisms regulating protection from oxidative stress. Aging cell. 2008; 7:506-515. [PubMed: 18419796]

Granado N, Ares-Santos S, Moratalla R. Methamphetamine and Parkinson's disease. Parkinson's disease. 2013; 2013:308052.

Greferath U, Mallard C, Roufail E, Rees SM, Barrett GL, Bartlett PF. Expression of the p75 neurotrophin receptor by striatal cholinergic neurons following global ischemia in rats is associated with neuronal degeneration. Neuroscience letters. 2002; 332:57-60. [PubMed: 12377384]

Greilberger J, Koidl C, Greilberger M, Lamprecht M, Schroecksnadel K, Leblhuber F, Fuchs D, Oettl K. Malondialdehyde, carbonyl proteins and albumin-disulphide as useful oxidative markers in mild cognitive impairment and Alzheimer's disease. Free radical research. 2008; 42:633-638. [PubMed: 18654878]

Gupta N, Yucel YH. Glaucoma as a neurodegenerative disease. Current opinion in ophthalmology. 2007; 18:110-114. [PubMed: 17301611]

Haider L, Fischer MT, Frischer JM, Bauer J, Hoftberger R, Botond G, Esterbauer H, Binder CJ, Witztum JL, Lassmann H. Oxidative damage in multiple sclerosis lesions. Brain : a journal of neurology. 2011; 134:1914-1924. [PubMed: 21653539]

Haider L, Simeonidou C, Steinberger G, Hametner S, Grigoriadis N, Deretzi G, Kovacs GG, Kutzelnigg A, Lassmann H, Frischer JM. Multiple sclerosis deep grey matter: the relation between demyelination, neurodegeneration, inflammation and iron. Journal of neurology, neurosurgery, and psychiatry. 2014; 85:1386-1395.

Hanson AJ, Prasad JE, Nahreini P, Andreatta C, Kumar B, Yan XD, Prasad KN. Overexpression of amyloid precursor protein is associated with degeneration, decreased viability, and increased damage caused by neurotoxins (prostaglandins A1 and E2, hydrogen peroxide, and nitric oxide) in differentiated neuroblastoma cells. Journal of neuroscience research. 2003; 74:148-159. [PubMed: 13130517]

Hautanen A, Manttari M, Manninen V, Adlercreutz H. Gemfibrozil treatment is associated with elevated adrenal androgen, androstanediol glucuronide and cortisol levels in dyslipidemic men. 
The Journal of steroid biochemistry and molecular biology. 1994; 51:307-313. [PubMed: 7826893]

He X, Jittiwat J, Kim JH, Jenner AM, Farooqui AA, Patel SC, Ong WY. Apolipoprotein D modulates F2-isoprostane and 7-ketocholesterol formation and has a neuroprotective effect on organotypic hippocampal cultures after kainate-induced excitotoxic injury. Neuroscience letters. 2009; 455:183-186. [PubMed: 19429117]

Hogg N, Kalyanaraman B. Nitric oxide and lipid peroxidation. Biochimica et biophysica acta. 1999; 1411:378-384. [PubMed: 10320670]

Hu LF, Lu M, Tiong CX, Dawe GS, Hu G, Bian JS. Neuroprotective effects of hydrogen sulfide on Parkinson's disease rat models. Aging cell. 2010; 9:135-146. [PubMed: 20041858]

Hurley LL, Tizabi Y. Neuroinflammation, neurodegeneration, and depression. Neurotoxicity research. 2013; 23:131-144. [PubMed: 22895696]

Inman DM, Lambert WS, Calkins DJ, Horner PJ. alpha-Lipoic acid antioxidant treatment limits glaucoma-related retinal ganglion cell death and dysfunction. PloS one. 2013; 8:e65389. [PubMed: 23755225]

Itzhak Y, Martin JL, Ali SF. Methamphetamine- and 1-methyl-4-phenyl- 1,2,3, 6-tetrahydropyridineinduced dopaminergic neurotoxicity in inducible nitric oxide synthase-deficient mice. Synapse (New York, NY). 1999; 34:305-312.

Jing YH, Chen KH, Kuo PC, Pao CC, Chen JK. Neurodegeneration in streptozotocin-induced diabetic rats is attenuated by treatment with resveratrol. Neuroendocrinology. 2013; 98:116-127. [PubMed: 23486084]

Kamenetz F, Tomita T, Hsieh H, Seabrook G, Borchelt D, Iwatsubo T, Sisodia S, Malinow R. APP processing and synaptic function. Neuron. 2003; 37:925-937. [PubMed: 12670422]

Kamoun P. Endogenous production of hydrogen sulfide in mammals. Amino acids. 2004; 26:243-254. [PubMed: 15221504]

Kauppinen TM, Suh SW, Higashi Y, Berman AE, Escartin C, Won SJ, Wang C, Cho SH, Gan L, Swanson RA. Poly(ADP-ribose)polymerase-1 modulates microglial responses to amyloid beta. Journal of neuroinflammation. 2011; 8:152. [PubMed: 22051244]

Khan MM, Ahmad A, Ishrat T, Khan MB, Hoda MN, Khuwaja G, Raza SS, Khan A, Javed H, Vaibhav K, Islam F. Resveratrol attenuates 6-hydroxydopamine-induced oxidative damage and dopamine depletion in rat model of Parkinson's disease. Brain research. 2010; 1328:139-151. [PubMed: 20167206]

Kim HG, Moon M, Choi JG, Park G, Kim AJ, Hur J, Lee KT, Oh MS. Donepezil inhibits the amyloidbeta oligomer-induced microglial activation in vitro and in vivo. Neurotoxicology. 2014; 40:2332. [PubMed: 24189446]

Kim MY, Zhang T, Kraus WL. Poly(ADP-ribosyl)ation by PARP-1: 'PAR-laying' NAD+ into a nuclear signal. Genes \& development. 2005; 19:1951-1967. [PubMed: 16140981]

Kita T, Asanuma M, Miyazaki I, Takeshima M. Protective effects of phytochemical antioxidants against neurotoxin-induced degeneration of dopaminergic neurons. Journal of pharmacological sciences. 2014; 124:313-319. [PubMed: 24599140]

Kokaia Z, Andsberg G, Martinez-Serrano A, Lindvall O. Focal cerebral ischemia in rats induces expression of P75 neurotrophin receptor in resistant striatal cholinergic neurons. Neuroscience. 1998; 84:1113-1125. [PubMed: 9578399]

Kono Y. The production of nitrating species by the reaction between nitrite and hypochlorous acid. Biochemistry and molecular biology international. 1995; 36:275-283. [PubMed: 7663431]

Korolchuk VI, Rubinsztein DC. Regulation of autophagy by lysosomal positioning. Autophagy. 2011; 7:927-928. [PubMed: 21521941]

Kraemer BR, Snow JP, Vollbrecht P, Pathak A, Valentine WM, Deutch AY, Carter BD. A Role for the p75 Neurotrophin Receptor in Axonal Degeneration and Apoptosis Induced by Oxidative Stress. The Journal of biological chemistry. 2014; 289:21205-21216. [PubMed: 24939843]

Kriscenski-Perry E, Durham HD, Sheu SS, Figlewicz DA. Synergistic effects of low level stressors in an oxidative damage model of spinal motor neuron degeneration. Amyotrophic lateral sclerosis and other motor neuron disorders : official publication of the World Federation of Neurology, Research Group on Motor Neuron Diseases. 2002; 3:151-157. 
Kuhn DM, Francescutti-Verbeem DM, Thomas DM. Dopamine quinones activate microglia and induce a neurotoxic gene expression profile: relationship to methamphetamine-induced nerve ending damage. Annals of the New York Academy of Sciences. 2006; 1074:31-41. [PubMed: 17105901]

Lee Y, Kim YH, Park SJ, Huh JW, Kim SH, Kim SU, Kim JS, Jeong KJ, Lee KM, Hong Y, Lee SR, Chang KT. Insulin/IGF signaling-related gene expression in the brain of a sporadic Alzheimer's disease monkey model induced by intracerebroventricular injection of streptozotocin. Journal of Alzheimer's disease : JAD. 2014; 38:251-267. [PubMed: 23948941]

Leelarungrayub D, Saidee K, Pothongsunun P, Pratanaphon S, YanKai A, Bloomer RJ. Six weeks of aerobic dance exercise improves blood oxidative stress status and increases interleukin-2 in previously sedentary women. Journal of bodywork and movement therapies. 2011; 15:355-362. [PubMed: 21665113]

Lofrumento DD, Nicolardi G, Cianciulli A, De Nuccio F, La Pesa V, Carofiglio V, Dragone T, Calvello R, Panaro MA. Neuroprotective effects of resveratrol in an MPTP mouse model of Parkinson's-like disease: possible role of SOCS-1 in reducing pro-inflammatory responses. Innate immunity. 2014; 20:249-260. [PubMed: 23764428]

Lopez-Sanchez C, Martin-Romero FJ, Sun F, Luis L, Samhan-Arias AK, Garcia-Martinez V, Gutierrez-Merino C. Blood micromolar concentrations of kaempferol afford protection against ischemia/reperfusion-induced damage in rat brain. Brain research. 2007; 1182:123-137. [PubMed: 17950707]

Loscher W. Critical review of current animal models of seizures and epilepsy used in the discovery and development of new antiepileptic drugs. Seizure. 2011; 20:359-368. [PubMed: 21292505]

Madrigal JL, Moro MA, Lizasoain I, Lorenzo P, Leza JC. Stress-induced increase in extracellular sucrose space in rats is mediated by nitric oxide. Brain research. 2002; 938:87-91. [PubMed: 12031539]

Meulendyke KA, Pletnikov MV, Engle EL, Tarwater PM, Graham DR, Zink MC. Early minocycline treatment prevents a decrease in striatal dopamine in an SIV model of HIV-associated neurological disease. Journal of neuroimmune pharmacology : the official journal of the Society on NeuroImmune Pharmacology. 2012; 7:454-464. [PubMed: 22198699]

Militao GC, Ferreira PM, de Freitas RM. Effects of lipoic acid on oxidative stress in rat striatum after pilocarpine-induced seizures. Neurochemistry international. 2010; 56:16-20. [PubMed: 19715735]

Mohagheghi F, Khalaj L, Ahmadiani A, Rahmani B. Gemfibrozil pretreatment affecting antioxidant defense system and inflammatory, but not Nrf-2 signaling pathways resulted in female neuroprotection and male neurotoxicity in the rat models of global cerebral ischemia-reperfusion. Neurotoxicity research. 2013; 23:225-237. [PubMed: 22773136]

Mohammad G, Siddiquei MM, Abu El-Asrar AM. Poly (ADP-ribose) polymerase mediates diabetesinduced retinal neuropathy. Mediators of inflammation. 2013; 2013:510451. [PubMed: 24347828]

Moncada S, Bolanos JP. Nitric oxide, cell bioenergetics and neurodegeneration. Journal of neurochemistry. 2006; 97:1676-1689. [PubMed: 16805776]

Moszczynska A, Yamamoto BK. Methamphetamine oxidatively damages parkin and decreases the activity of $26 \mathrm{~S}$ proteasome in vivo. Journal of neurochemistry. 2011; 116:1005-1017. [PubMed: 21166679]

Niswender KD, Daws LC, Avison MJ, Galli A. Insulin regulation of monoamine signaling: pathway to obesity. Neuropsychopharmacology : official publication of the American College of Neuropsychopharmacology. 2011; 36:359-360. [PubMed: 21116253]

O'Donnell VB, Eiserich JP, Chumley PH, Jablonsky MJ, Krishna NR, Kirk M, Barnes S, DarleyUsmar VM, Freeman BA. Nitration of unsaturated fatty acids by nitric oxide-derived reactive nitrogen species peroxynitrite, nitrous acid, nitrogen dioxide, and nitronium ion. Chemical research in toxicology. 1999; 12:83-92. [PubMed: 9894022]

Pallas M, Porquet D, Vicente A, Sanfeliu C. Resveratrol: new avenues for a natural compound in neuroprotection. Current pharmaceutical design. 2013; 19:6726-6731. [PubMed: 23530512]

Pangeni R, Sharma S, Mustafa G, Ali J, Baboota S. Vitamin E loaded resveratrol nanoemulsion for brain targeting for the treatment of Parkinson's disease by reducing oxidative stress. Nanotechnology. 2014; 25:485102. [PubMed: 25392203] 
Park S, Geddes TJ, Javitch JA, Kuhn DM. Dopamine prevents nitration of tyrosine hydroxylase by peroxynitrite and nitrogen dioxide: is nitrotyrosine formation an early step in dopamine neuronal damage? The Journal of biological chemistry. 2003; 278:28736-28742. [PubMed: 12771134]

Perez-Asensio FJ, de la Rosa X, Jimenez-Altayo F, Gorina R, Martinez E, Messeguer A, Vila E, Chamorro A, Planas AM. Antioxidant CR-6 protects against reperfusion injury after a transient episode of focal brain ischemia in rats. Journal of cerebral blood flow and metabolism : official journal of the International Society of Cerebral Blood Flow and Metabolism. 2010; 30:638-652.

Perry VH, Holmes C. Microglial priming in neurodegenerative disease. Nature reviews Neurology. 2014; 10:217-224. [PubMed: 24638131]

Pieper AA, Verma A, Zhang J, Snyder SH. Poly (ADP-ribose) polymerase, nitric oxide and cell death. Trends in pharmacological sciences. 1999; 20:171-181. [PubMed: 10322503]

Pong K. Oxidative stress in neurodegenerative diseases: therapeutic implications for superoxide dismutase mimetics. Expert opinion on biological therapy. 2003; 3:127-139. [PubMed: 12718737]

Prasad JE, Kumar B, Andreatta C, Nahreini P, Hanson AJ, Yan XD, Prasad KN. Overexpression of alpha-synuclein decreased viability and enhanced sensitivity to prostaglandin $\mathrm{E}(2)$, hydrogen peroxide, and a nitric oxide donor in differentiated neuroblastoma cells. Journal of neuroscience research. 2004; 76:415-422. [PubMed: 15079871]

Quincozes-Santos A, Bobermin LD, Latini A, Wajner M, Souza DO, Goncalves CA, Gottfried C. Resveratrol protects C6 astrocyte cell line against hydrogen peroxide-induced oxidative stress through heme oxygenase 1. PloS one. 2013; 8:e64372. [PubMed: 23691207]

Radi R. Peroxynitrite, a stealthy biological oxidant. The Journal of biological chemistry. 2013a; 288:26464-26472. [PubMed: 23861390]

Radi R. Protein tyrosine nitration: biochemical mechanisms and structural basis of functional effects. Accounts of chemical research. 2013b; 46:550-559. [PubMed: 23157446]

Rawji KS, Yong VW. The benefits and detriments of macrophages/microglia in models of multiple sclerosis. Clinical \& developmental immunology. 2013; 2013:948976. [PubMed: 23840244]

Rebillard A, Lefeuvre-Orfila L, Gueritat J, Cillard J. Prostate cancer and physical activity: adaptive response to oxidative stress. Free radical biology \& medicine. 2013; 60:115-124. [PubMed: 23462616]

Rege SD, Geetha T, Griffin GD, Broderick TL, Babu JR. Neuroprotective effects of resveratrol in Alzheimer disease pathology. Frontiers in aging neuroscience. 2014; 6:218. [PubMed: 25309423]

Rege SD, Kumar S, Wilson DN, Tamura L, Geetha T, Mathews ST, Huggins KW, Broderick TL, Babu JR. Resveratrol protects the brain of obese mice from oxidative damage. Oxidative medicine and cellular longevity. 2013; 2013:419092. [PubMed: 24163719]

Rejdak K, Eikelenboom MJ, Petzold A, Thompson EJ, Stelmasiak Z, Lazeron RH, Barkhof F, Polman $\mathrm{CH}$, Uitdehaag BM, Giovannoni G. CSF nitric oxide metabolites are associated with activity and progression of multiple sclerosis. Neurology. 2004; 63:1439-1445. [PubMed: 15505162]

Rejdak K, Petzold A, Stelmasiak Z, Giovannoni G. Cerebrospinal fluid brain specific proteins in relation to nitric oxide metabolites during relapse of multiple sclerosis. Multiple sclerosis (Houndmills, Basingstoke, England). 2008; 14:59-66.

Rodriguez E, Rivera I, Astorga S, Mendoza E, Garcia F, Hernandez-Echeagaray E. Uncoupling oxidative/energy metabolism with low sub chronic doses of 3-nitropropionic acid or iodoacetate in vivo produces striatal cell damage. International journal of biological sciences. 2010; 6:199212. [PubMed: 20440403]

Roy A, Fung YK, Liu X, Pahan K. Up-regulation of microglial CD11b expression by nitric oxide. The Journal of biological chemistry. 2006; 281:14971-14980. [PubMed: 16551637]

Rubbo H, Radi R. Protein and lipid nitration: role in redox signaling and injury. Biochimica et biophysica acta. 2008; 1780:1318-1324. [PubMed: 18395525]

Rudolph TK, Freeman BA. Transduction of redox signaling by electrophile-protein reactions. Science signaling. 2009; 2:re7. [PubMed: 19797270]

Ryu JK, Choi HB, McLarnon JG. Combined minocycline plus pyruvate treatment enhances effects of each agent to inhibit inflammation, oxidative damage, and neuronal loss in an excitotoxic animal model of Huntington's disease. Neuroscience. 2006; 141:1835-1848. [PubMed: 16809003] 
Sandhir R, Yadav A, Mehrotra A, Sunkaria A, Singh A, Sharma S. Curcumin nanoparticles attenuate neurochemical and neurobehavioral deficits in experimental model of Huntington's disease. Neuromolecular medicine. 2014; 16:106-118. [PubMed: 24008671]

Sarkar S, Korolchuk VI, Renna M, Imarisio S, Fleming A, Williams A, Garcia-Arencibia M, Rose C, Luo S, Underwood BR, Kroemer G, O'Kane CJ, Rubinsztein DC. Complex inhibitory effects of nitric oxide on autophagy. Molecular cell. 2011; 43:19-32. [PubMed: 21726807]

Shchepinov MS, Chou VP, Pollock E, Langston JW, Cantor CR, Molinari RJ, Manning-Bog AB. Isotopic reinforcement of essential polyunsaturated fatty acids diminishes nigrostriatal degeneration in a mouse model of Parkinson's disease. Toxicology letters. 2011; 207:97-103. [PubMed: 21906664]

Shichiri M. The role of lipid peroxidation in neurological disorders. Journal of clinical biochemistry and nutrition. 2014; 54:151-160. [PubMed: 24895477]

Shin EJ, Jeong JH, Bing G, Park ES, Chae JS, Yen TP, Kim WK, Wie MB, Jung BD, Kim HJ, Lee SY, Kim HC. Kainate-induced mitochondrial oxidative stress contributes to hippocampal degeneration in senescence-accelerated mice. Cellular signalling. 2008a; 20:645-658. [PubMed: 18248956]

Shin EJ, Ko KH, Kim WK, Chae JS, Yen TP, Kim HJ, Wie MB, Kim HC. Role of glutathione peroxidase in the ontogeny of hippocampal oxidative stress and kainate seizure sensitivity in the genetically epilepsy-prone rats. Neurochemistry international. 2008b; 52:1134-1147. [PubMed: 18226427]

Silva-Adaya D, Perez-De La Cruz V, Herrera-Mundo MN, Mendoza-Macedo K, Villeda-Hernandez J, Binienda Z, Ali SF, Santamaria A. Excitotoxic damage, disrupted energy metabolism, and oxidative stress in the rat brain: antioxidant and neuroprotective effects of L-carnitine. Journal of neurochemistry. 2008; 105:677-689. [PubMed: 18194214]

Skundric DS, Lisak RP. Role of neuropoietic cytokines in development and progression of diabetic polyneuropathy: from glucose metabolism to neurodegeneration. Experimental diabesity research. 2003; 4:303-312. [PubMed: 14668051]

Smith KJ, Lassmann H. The role of nitric oxide in multiple sclerosis. Lancet neurology. 2002; 1:232241. [PubMed: 12849456]

Stavniichuk R, Shevalye H, Lupachyk S, Obrosov A, Groves JT, Obrosova IG, Yorek MA. Peroxynitrite and protein nitration in the pathogenesis of diabetic peripheral neuropathy. Diabetes/metabolism research and reviews. 2014; 30:669-678. [PubMed: 24687457]

Stoy N, Mackay GM, Forrest CM, Christofides J, Egerton M, Stone TW, Darlington LG. Tryptophan metabolism and oxidative stress in patients with Huntington's disease. Journal of neurochemistry. 2005; 93:611-623. [PubMed: 15836620]

Strauss KI. Antiinflammatory and neuroprotective actions of COX2 inhibitors in the injured brain. Brain, behavior, and immunity. 2008; 22:285-298.

Strosznajder JB, Czapski GA, Adamczyk A, Strosznajder RP. Poly(ADP-ribose) polymerase-1 in amyloid beta toxicity and Alzheimer's disease. Molecular neurobiology. 2012; 46:78-84. [PubMed: 22430645]

Sultana R, Perluigi M, Allan Butterfield D. Lipid peroxidation triggers neurodegeneration: a redox proteomics view into the Alzheimer disease brain. Free radical biology \& medicine. 2013; 62:157-169. [PubMed: 23044265]

Suo S, Ishiura S. Dopamine modulates acetylcholine release via octopamine and CREB signaling in Caenorhabditis elegans. PloS one. 2013; 8:e72578. [PubMed: 23977320]

Szumiel I. Autophagy, reactive oxygen species and the fate of mammalian cells. Free radical research. 2011; 45:253-265. [PubMed: 20964552]

Szutowicz A, Bielarczyk H, Jankowska-Kulawy A, Pawelczyk T, Ronowska A. Acetyl-CoA the key factor for survival or death of cholinergic neurons in course of neurodegenerative diseases. Neurochemical research. 2013; 38:1523-1542. [PubMed: 23677775]

Tabet N. Acetylcholinesterase inhibitors for Alzheimer's disease: anti-inflammatories in acetylcholine clothing! Age and ageing. 2006; 35:336-338. [PubMed: 16788077] 
Tan B, Choi RH, Chin TJ, Kaur C, Ling EA. Manipulation of microglial activity as a therapy for Alzheimer's disease. Frontiers in bioscience (Scholar edition). 2012; 4:1402-1412. [PubMed: 22652882]

Thomas B, Beal MF. Parkinson's disease. Human molecular genetics. 2007; 16:R183-194. Spec No. 2. [PubMed: 17911161]

Thomas DM, Francescutti-Verbeem DM, Kuhn DM. Gene expression profile of activated microglia under conditions associated with dopamine neuronal damage. FASEB journal : official publication of the Federation of American Societies for Experimental Biology. 2006; 20:515517. [PubMed: 16384912]

Thomas DM, Francescutti-Verbeem DM, Kuhn DM. The newly synthesized pool of dopamine determines the severity of methamphetamine-induced neurotoxicity. Journal of neurochemistry. 2008; 105:605-616. [PubMed: 18088364]

Ting JT, Kelley BG, Lambert TJ, Cook DG, Sullivan JM. Amyloid precursor protein overexpression depresses excitatory transmission through both presynaptic and postsynaptic mechanisms. Proceedings of the National Academy of Sciences of the United States of America. 2007; 104:353-358. [PubMed: 17185415]

Trudel S, Trecherel E, Gomila C, Peltier M, Aubignat M, Gubler B, Morliere P, Heard JM, Ausseil J. Oxidative stress is independent of inflammation in the neurodegenerative sanfilippo syndrome type B. Journal of neuroscience research. 2014

Tsang AH, Lee YI, Ko HS, Savitt JM, Pletnikova O, Troncoso JC, Dawson VL, Dawson TM, Chung KK. S-nitrosylation of XIAP compromises neuronal survival in Parkinson's disease. Proceedings of the National Academy of Sciences of the United States of America. 2009; 106:4900-4905. [PubMed: 19273858]

Tully M, Shi R. New insights in the pathogenesis of multiple sclerosis--role of acrolein in neuronal and myelin damage. International journal of molecular sciences. 2013; 14:20037-20047. [PubMed: 24113583]

Turner BJ, Cheah IK, Macfarlane KJ, Lopes EC, Petratos S, Langford SJ, Cheema SS. Antisense peptide nucleic acid-mediated knockdown of the p75 neurotrophin receptor delays motor neuron disease in mutant SOD1 transgenic mice. Journal of neurochemistry. 2003; 87:752-763. [PubMed: 14535957]

Turunc Bayrakdar E, Uyanikgil Y, Kanit L, Koylu E, Yalcin A. Nicotinamide treatment reduces the levels of oxidative stress, apoptosis, and PARP-1 activity in Abeta(1-42)-induced rat model of Alzheimer's disease. Free radical research. 2014; 48:146-158. [PubMed: 24151909]

Uehara T, Nakamura T, Yao D, Shi ZQ, Gu Z, Ma Y, Masliah E, Nomura Y, Lipton SA. Snitrosylated protein-disulphide isomerase links protein misfolding to neurodegeneration. Nature. 2006; 441:513-517. [PubMed: 16724068]

Umegaki H. Neurodegeneration in diabetes mellitus. Advances in experimental medicine and biology. 2012; 724:258-265. [PubMed: 22411248]

Vareniuk I, Pacher P, Pavlov IA, Drel VR, Obrosova IG. Peripheral neuropathy in mice with neuronal nitric oxide synthase gene deficiency. International journal of molecular medicine. 2009; 23:571580. [PubMed: 19360314]

Vareniuk I, Pavlov IA, Drel VR, Lyzogubov VV, Ilnytska O, Bell SR, Tibrewala J, Groves JT, Obrosova IG. Nitrosative stress and peripheral diabetic neuropathy in leptin-deficient (ob/ob) mice. Experimental neurology. 2007; 205:425-436. [PubMed: 17475250]

Vareniuk I, Pavlov IA, Obrosova IG. Inducible nitric oxide synthase gene deficiency counteracts multiple manifestations of peripheral neuropathy in a streptozotocin-induced mouse model of diabetes. Diabetologia. 2008; 51:2126-2133. [PubMed: 18802679]

Villani GR, Di Domenico C, Musella A, Cecere F, Di Napoli D, Di Natale P. Mucopolysaccharidosis IIIB: oxidative damage and cytotoxic cell involvement in the neuronal pathogenesis. Brain research. 2009; 1279:99-108. [PubMed: 19409882]

Vinik AI, Nevoret ML, Casellini C, Parson H. Diabetic neuropathy. Endocrinology and metabolism clinics of North America. 2013; 42:747-787. [PubMed: 24286949] 
Wang YQ, Bian GL, Bai Y, Cao R, Chen LW. Identification and kainic acid-induced up-regulation of low-affinity p75 neurotrophin receptor (p75NTR) in the nigral dopamine neurons of adult rats. Neurochemistry international. 2008; 53:56-62. [PubMed: 18639597]

Williams JM, Owens WA, Turner GH, Saunders C, Dipace C, Blakely RD, France CP, Gore JC, Daws LC, Avison MJ, Galli A. Hypoinsulinemia regulates amphetamine-induced reverse transport of dopamine. PLoS biology. 2007; 5:e274. [PubMed: 17941718]

Winterbourn CC. Toxicity of iron and hydrogen peroxide: the Fenton reaction. Toxicology letters. 1995; 82-83:969-974. [PubMed: 8597169]

Wong ES, Tan JM, Wang C, Zhang Z, Tay SP, Zaiden N, Ko HS, Dawson VL, Dawson TM, Lim KL. Relative sensitivity of parkin and other cysteine-containing enzymes to stress-induced solubility alterations. The Journal of biological chemistry. 2007; 282:12310-12318. [PubMed: 17329252]

Wu DC, Jackson-Lewis V, Vila M, Tieu K, Teismann P, Vadseth C, Choi DK, Ischiropoulos H, Przedborski S. Blockade of microglial activation is neuroprotective in the 1-methyl-4phenyl-1,2,3,6-tetrahydropyridine mouse model of Parkinson disease. The Journal of neuroscience : the official journal of the Society for Neuroscience. 2002; 22:1763-1771. [PubMed: 11880505]

Yenari MA, Kauppinen TM, Swanson RA. Microglial activation in stroke: therapeutic targets. Neurotherapeutics : the journal of the American Society for Experimental NeuroTherapeutics. 2010; 7:378-391. [PubMed: 20880502]

Yeo WS, Kim YJ, Kabir MH, Kang JW, Kim KP. Mass spectrometric analysis of protein tyrosine nitration in aging and neurodegenerative diseases. Mass spectrometry reviews. 2014

Yrjanheikki J, Keinanen R, Pellikka M, Hokfelt T, Koistinaho J. Tetracyclines inhibit microglial activation and are neuroprotective in global brain ischemia. Proceedings of the National Academy of Sciences of the United States of America. 1998; 95:15769-15774. [PubMed: 9861045]

Zahid M, Saeed M, Yang L, Beseler C, Rogan E, Cavalieri EL. Formation of dopamine quinone-DNA adducts and their potential role in the etiology of Parkinson's disease. IUBMB life. 2011; 63:1087-1093. [PubMed: 22045657]

Zaja-Milatovic S, Gupta RC, Aschner M, Montine TJ, Milatovic D. Pharmacologic suppression of oxidative damage and dendritic degeneration following kainic acid-induced excitotoxicity in mouse cerebrum. Neurotoxicology. 2008; 29:621-627. [PubMed: 18556069]

Zhang F, Shi JS, Zhou H, Wilson B, Hong JS, Gao HM. Resveratrol protects dopamine neurons against lipopolysaccharide-induced neurotoxicity through its anti-inflammatory actions. Molecular pharmacology. 2010; 78:466-477. [PubMed: 20554604]

Zhang L, Zhou FM, Dani JA. Cholinergic drugs for Alzheimer's disease enhance in vitro dopamine release. Molecular pharmacology. 2004; 66:538-544. [PubMed: 15322245]

Zhou J, Zhou S. Inflammation: therapeutic targets for diabetic neuropathy. Molecular neurobiology. 2014; 49:536-546. [PubMed: 23990376]

Zuccato C, Valenza M, Cattaneo E. Molecular mechanisms and potential therapeutical targets in Huntington's disease. Physiological reviews. 2010; 90:905-981. [PubMed: 20664076] 


\section{Highlights}

- The brain is sensitive to oxidative/nitrative stress

- Redox cycling is central to microglial activation, dopamine, and diabetes

- Oxidative stress triggers microglial activation and neuroinflammation

- Antioxidant treatments may mediate neuroprotection during oxidative/nitrative stress 


\section{Lipid Peroxidation}

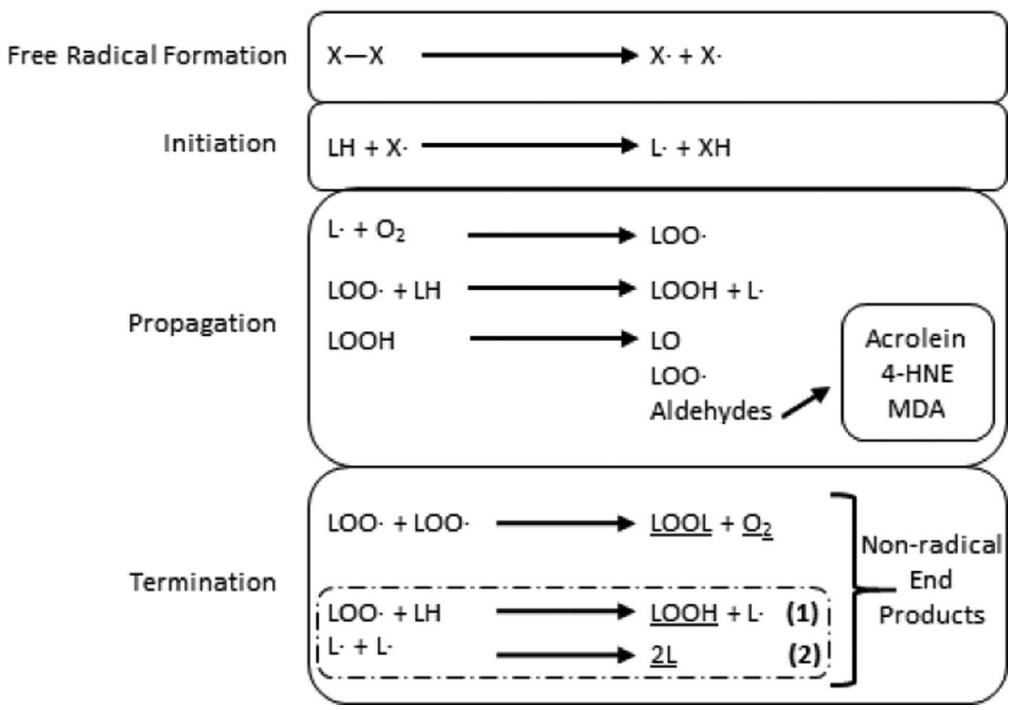

Figure 1. General mechanism of lipid peroxidation

Lipid peroxidation requires three major steps. After free radicals are formed, the initation step begins via free radical attack and proton abstraction from an unsaturated lipid to form a lipid radical. Propagation ensues when the lipid radical reacts with molecular oxygen or another unsaturated lipid to form a lipoperoxyl radical or regenerate a new lipid radical, respectively. It is during propagation that reactive aldehydes are formed. Propagation continues until termination is reached to form non-radical end products (underlined). The coupled reactions (dashed box) require two rounds of (1) to take place for (2) to succeed it and terminate lipid peroxidation by production of $2 \mathrm{~L}$. $\mathrm{X}$ and $\mathrm{L}$ refer to any reactive species or lipid species, respectively. 


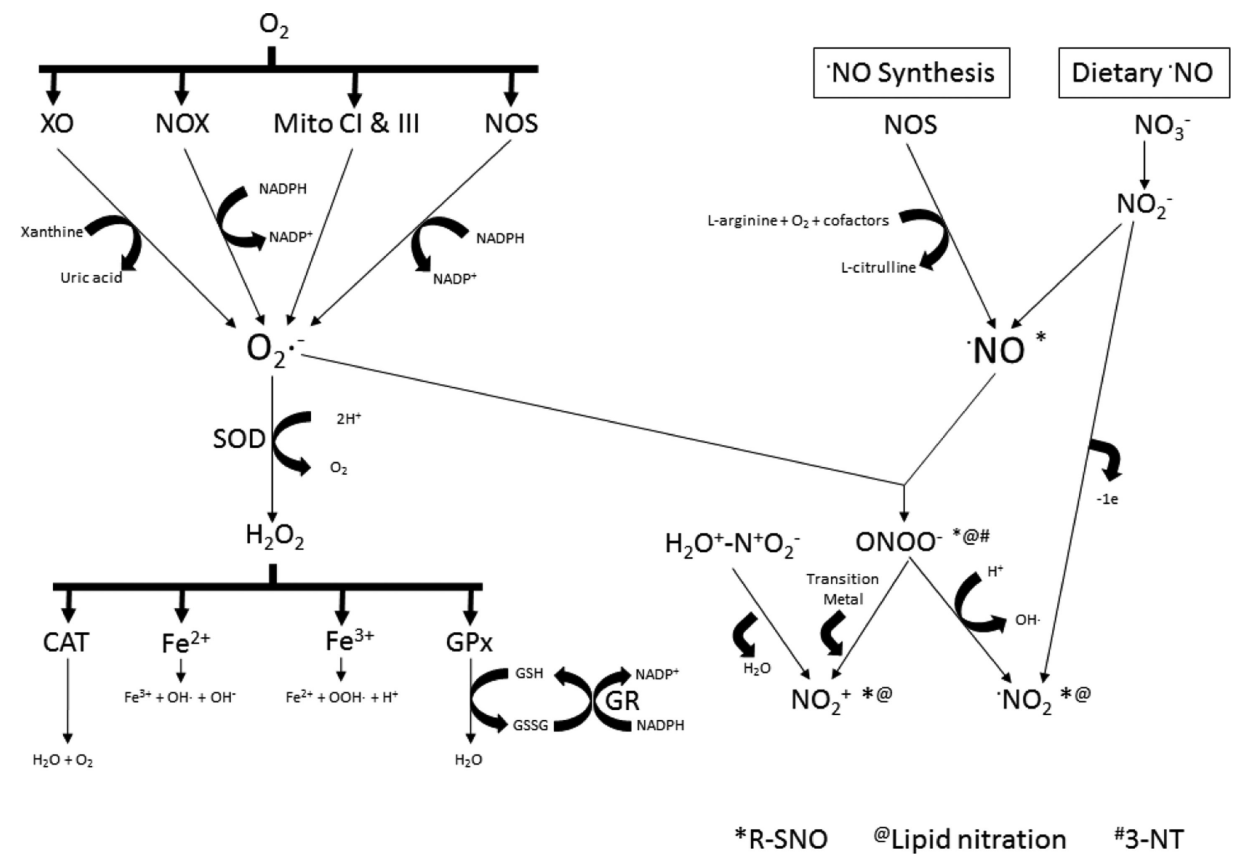

Figure 2. Mechanisms of ROS/RNS generation and downstream modifications

Molecular oxygen is a substrate for xanthine oxidase, NADPH oxidases, mitochondrial complexes I and III, and uncoupled nitric oxide synthases to form superoxide. Superoxide is detoxified by forming hydrogen peroxide via superoxide dismutase activity or can react with nitric oxide to form peroxynitrite. Hydrogen peroxide is cleared by cells through catalase, glutathione peroxidase/glutathione reductase (GR), and iron. Nitric oxide is formed from dietary nitrate to nitrite or from coupled nitric oxide synthases. Nitrite decomposition and peroxynitrite acidification form nitrogen dioxide radicals. Nitrogen dioxide in the presence of water and sulfuric acid results in nitronium or nitryl ion formation and is reversible. Nitronium ions also result from peroxynitrite's reaction with a transition metal. Species responsible for protein S-nitrosylation, lipid nitration, and 3-nitrotyrosine production are indicated as marked with *, @ ${ }^{\text {\# }}$, respectively. 


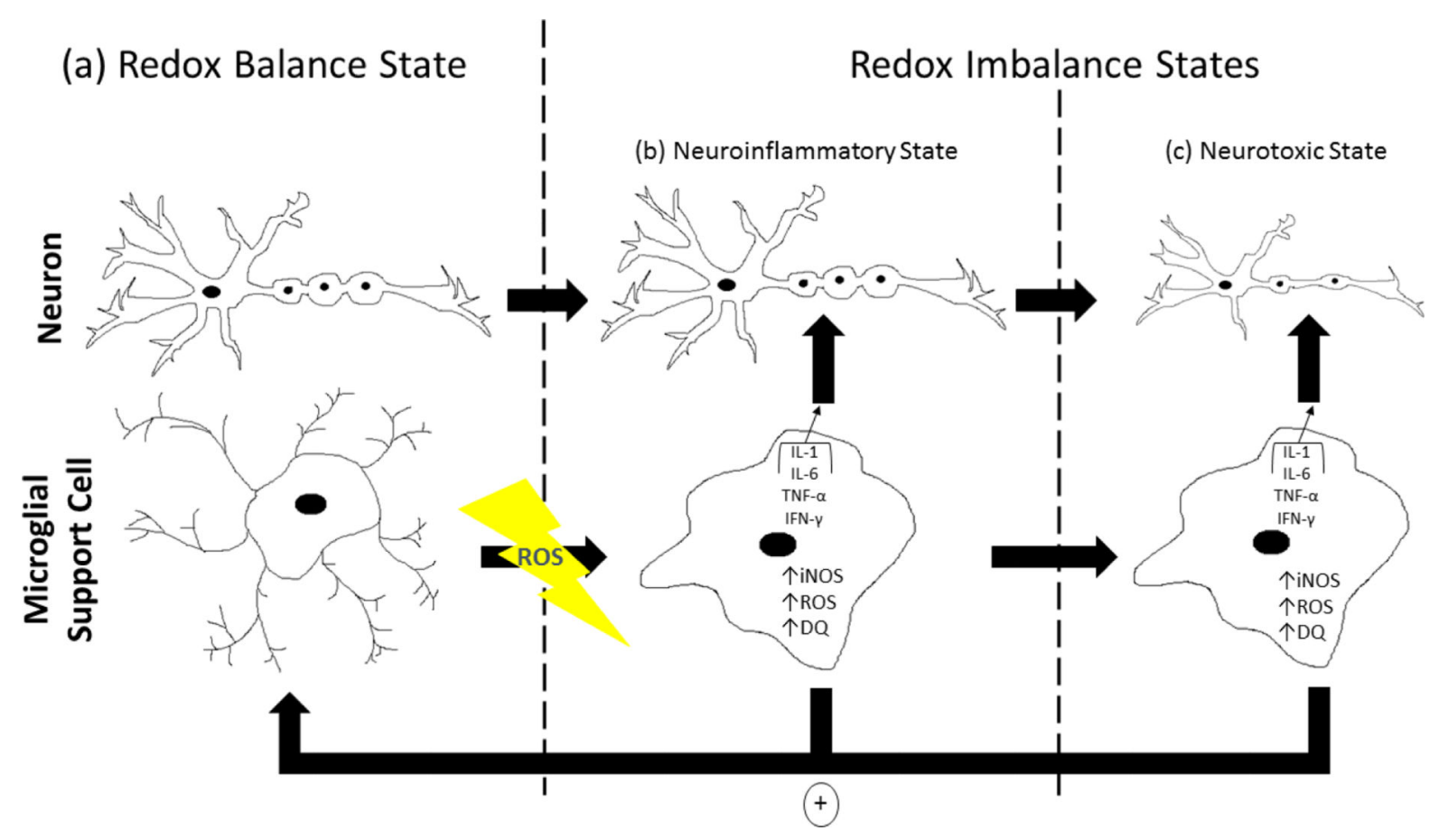

Figure 3. A model for oxidative stress-induced microglial activation in regulating neurodegeneration

In a redox balanced state, both neurons and their support cells coexist in a healthy environment with ROS/RNS in homeostasis. Neurons exhibit normal morphology while microglial cells are in their inactive resting state (a). Upon induction of oxidative/nitrative stress in a redox imbalanced state, a neuroinflammatory condition is established by activation of microglia which undergo morphological changes as ROS/RNS-producing factories through upregulation and release of cytokines such as interleukin-1, interleukin-6, tumor necrosis factor- $a$, and interferon- $\gamma$; iNOS upregulation, which increases NO levels; increased ROS production; and stimulation of dopaminequinone formation where dopaminequinones down regulate neuroprotective gene expression (b, c). Activated microglia function in two ways: (1) to activate neighboring microglial cells or sustain activation of already activated microglia in a positive feedback mechanism (denoted by the circled + sign) and (2) to act on neurons causing several characteristic changes. In the presence of activated microglia, neurons can exhibit cell shrinkage and reduced axonal and dendrite length, myelin insulation, spine density, nerve conductance, and neurotransmitter transmission. These effects mediate the transition into the neurotoxic state and are initiated by activated microglia. 


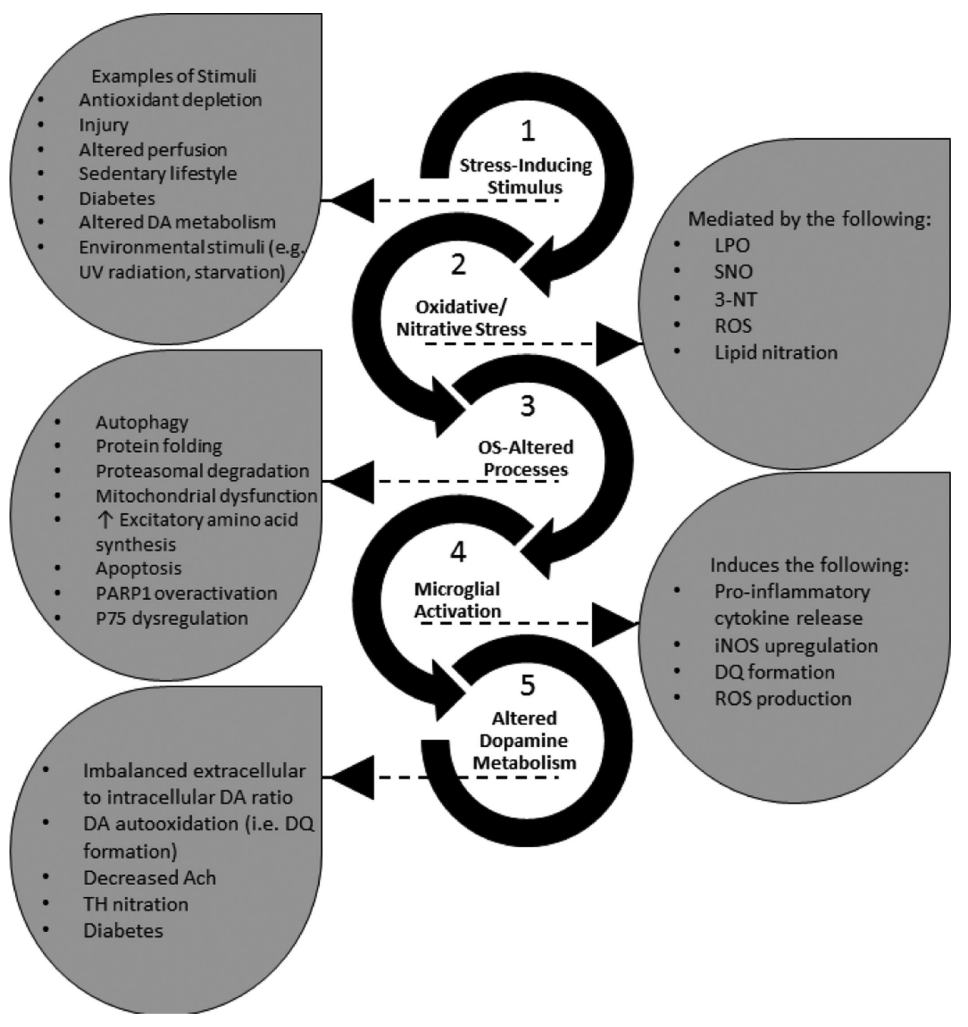

Figure 4. A model for the interplay among oxidative stress, microglial activation, dopamine metabolism, and diabetes

The process by which OS leads to neurodegeneration is detailed in the solid black arrows, whereas the details of each are noted in solid gray to the left and right. (1) An oxidative/ nitrative stress-inducing stimulus, for example antioxidant depletion or altered dopamine metabolism, occurs in the brain. (2) Consequent stress follows, mediated by redox cycling through ROS/RNS, LPO products, or lipid or protein modifications. (3) Once oxidative/ nitrative stress mediators are present, cellular processes undergo modifications and/or fluctuations, such as declines in autophagy or PARP1 over activation. (4) Oxidative/nitrative stress and changes in these processes lead to microglial activation, which causes secretion of several pro-inflammatory cytokines, iNOS upregulation, dopamine-quinone production, and potentiated ROS/RNS production, all of which can alone cause further microglial activation. (5) Microglial activation acts on dopamine metabolism. Examples of vacillations in dopamine metabolism are caused by shifts in the extracellular and intracellular dopamine pools, dopamine autooxidation, decreased acetylcholine synthesis or availability, tyrosine hydroxylase nitration, and onset of diabetes. 